(C) 2018. This manuscript version is made available under the CC-BY-NC-ND 4.0 license http:// creativecommons.org/licenses/by-nc-nd/4.0/

\title{
MODEL-BASED ASSESSMENT OF ENERGY-EFFICIENCY, DEPENDABILITY, AND COST-EFFECTIVENESS OF WASTE HEAT RECOVERY SYSTEMS ONBOARD SHIP
}

Jörg Lampe ${ }^{\mathrm{a}, *}$, Erich Rüde ${ }^{\mathrm{a}}$, Yiannis Papadopoulos ${ }^{\mathrm{b}}$, Sohag Kabir ${ }^{\mathrm{b}}$

${ }^{a}$ DNV GL SE, Hamburg, 20457, Brooktorkai 18, Germany

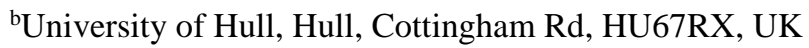

\section{ABSTRACT}

9 Technological systems are not merely designed with a narrow function in mind. Good designs typically aim at reducing 10 operational costs, e.g. through achieving high energy efficiency and improved dependability (i.e. reliability, availability

11 and maintainability). When there is a choice of alternative design options that perform the same function, it makes sense

12 to compare alternatives so that the variant that minimises operational costs can be selected. In this paper, we examine

13 this issue in the context of the design of Waste Heat Recovery Systems (WHRS) for main engines of large commercial

14 freight vessels. We propose a method that can predict the operational cost of a WHRS via thermodynamic analysis

15 which shows costs related to energy utilisation, and dependability analysis which shows costs related to system

16 unavailability and repair. Our approach builds on recent advances in thermodynamic simulation and compositional

17 dependability analysis techniques. It is a model-based approach, and allows reuse of component libraries, and a high

18 degree of automation which simplify application of the method. Our case study shows that alternative designs can be

19 explored in fast iterations of this method, and that this facilitates the evidence-based selection of a design that minimises

20 operational costs.

\section{KEYWORDS}

22 Energy efficiency, green shipping, energy flow simulation, reliability, availability, economic assessment

\section{ABBREVIATIONS}

$\begin{array}{lll}24 & T & \text { Temperature }(\mathrm{K}) \\ 25 & \Delta T & \text { Temperature difference }(\mathrm{K}) \\ 26 & \dot{m} & \text { Mass flow }\left(\mathrm{kg} \mathrm{s}^{-1}\right) \\ 27 & p & \text { Pressure }\left(\mathrm{N} \mathrm{m}^{-2}\right) \\ 28 & c_{P} & \text { Specific heat capacity }\left(\mathrm{J} \mathrm{kg}^{-1} \mathrm{~K}^{-1}\right) \\ 29 & P & \text { Power }\left(\mathrm{J} \mathrm{s}^{-1}\right) \\ 30 & h & \text { Specific enthalpy }\left(\mathrm{J} \mathrm{kg}^{-1}\right)\end{array}$

\footnotetext{
*Corresponding Author. Email: Joerg.Lampe@dnvgl.com (Jörg Lampe), Erich.Ruede@dnvgl.com (Erich Rüde), Y.I.Papadopoulos@hull.ac.uk (Yiannis Papadopoulos), S.Kabir@hull.ac.uk (Sohag Kabir)
} 


\begin{tabular}{|c|c|c|}
\hline 1 & $\dot{Q}$ & Heat flow $\left(\mathrm{J} \mathrm{s}^{-1}\right)$ \\
\hline 2 & $\eta$ & Efficiency \\
\hline 3 & $\gamma$ & Specific heat ratio \\
\hline 4 & $\lambda$ & Failure rate \\
\hline 5 & Exc & Excess output (deviation class) \\
\hline 6 & $F(t)$ & Failure probability (unreliability) \\
\hline 7 & FTA & Fault Tree Analysis \\
\hline 8 & $\mathrm{HE}$ & Heat Exchanger \\
\hline 9 & $\mathrm{HFO}$ & Heavy Fuel Oil \\
\hline 10 & HP & High Pressure \\
\hline 11 & HRSG & Heat Recovery Steam Generator \\
\hline 12 & $\dot{L}$ & Mechanical power $(\mathrm{W})$ \\
\hline 13 & LP & Low Pressure \\
\hline 14 & Low & Low output (deviation class) \\
\hline 15 & LowLow & Very low output (deviation class) \\
\hline 16 & MCR & Maximum Continuous Rating \\
\hline 17 & MCS & Minimal Cut Set \\
\hline 18 & MDO & Marine Diesel Oil \\
\hline 19 & ME & Main Engine \\
\hline 20 & Om & Omission of output (deviation class) \\
\hline 21 & PT & (Exhaust gas) Power Turbine \\
\hline 22 & $Q(t)$ & Unavailability \\
\hline 23 & $R(t)$ & Reliability \\
\hline 24 & Red & Reduced output (deviation class) \\
\hline 25 & ST & Steam Turbine \\
\hline 26 & ST1 & Single pressure Steam Turbine \\
\hline 27 & ST2PT & Combined dual pressure Steam Turbine with Power Turbine \\
\hline 28 & $t$ & (Operational) time \\
\hline 29 & WHRS & Waste Heat Recovery System \\
\hline
\end{tabular}




\section{Introduction}

2 Minimising operational costs is a worthwhile goal for most industrial systems. We contextualise this goal within current

3 developments in the regulatory and technological environment in the shipping industry. A major part of the operating

4 cost of ocean vessels is directly related to fuel oil. This cost can be reduced by improving energy efficiency, clearly an

5 area where economics aligns with environmental concerns. The move for energy efficiency is indeed also driven by

6 increasingly tight environmental regulations, specially by the $\mathrm{IMO}$ and $\mathrm{EU}$, aiming at the reduction of $\mathrm{CO}_{2}$ emissions

7 (Lampe and Freund, 2013).

8 Combustion engines onboard ship, only convert around 50\% of the fuel energy into propulsion. The other half is lost to

9 the environment mainly as heat energy via the cooling system $(\sim 20 \%)$ and the exhaust gas system $(\sim 25 \%)$. The heat

10 energy contained in exhaust gases is partly recoverable via use of Waste Heat Recovery Systems (WHRS) (MAN Diesel

$11 \&$ Turbo, 2012). Currently, WHRS can boost the energy efficiency of the main engine by more than $10 \%$. This is

12 achieved by generating electrical power to serve electrical consumers and/or acting as additional power source for

13 propulsion through a shaft motor.

14 The topic of WHR has already been addressed in the textbooks Reay (1979), Thurmann (1983) and Goldstick and

15 Thurman (1985) over 30 years ago. A survey for the US department of energy (Energetics 2004) reviewed energy

16 recovery in industrial energy systems, and Junior et al. (20016) compiled current research in Energy Management, Air

17 Conditioning and WHR in conference proceedings. Recent work with a special focus in maritime applications can e.g.

18 be found in Adamkiewicz and Wietrzyk (2012) with an overview over currently available WHR systems regarding

19 efficiency and savings; whereas in Zou et al. (2013) detailed model simulations are validated by available

20 measurements.

21 WHRS introduce energy and cost gains but also entail new costs: purchase and installation costs, as well as costs related

22 to their failure, repair and maintenance. To estimate the latter, dependability analysis of the system is required so that

23 costs related to failure and repair can be established. This in turn can feed into calculations on payback period and cost

24 savings from the introduction of a WHRS. Dependability analysis encompasses prediction of reliability and availability

25 and should take maintenance into account as it prolongs the useful life of the system. Indeed, reduced availability will

26 have significant impact on costs, especially if repairs cannot be executed at sea, but require the ship to reach the next

27 harbour or even to go to dry dock.

28 In the past, researchers have performed reliability, availability and cost analysis of energy systems. Haghifam and

29 Manbachi (2011) have proposed a methodology for the thermal and electrical reliability and availability analysis of

30 combined heat and power (CHP) systems. The method was based on Markov model and it considered three important 
subsystems of the CHP namely the electricity-generation, fuel-distribution, and heat-generation subsystems. On the other hand, Wang et al. (2013) used Markov model to perform reliability and availability analysis of redundant building cooling, heating and power (BCHP) system. It was showed that the redundant design of the $\mathrm{BCHP}$ is more reliable than the non-redundant BCHP design. As these approaches used Markov model for reliability analysis, for general application they may suffer from state-space explosion. Koeppel and Andersson (2009) proposed a method for reliability modelling of multi carrier energy systems. In the analysis, the authors consider the dependency and redundancy introduced due to the mutual conversion among different energy sources (e.g., thermal to electrical energy), and evaluate the reliability of supply in terms of the reliability characteristics of the existing conversions. Similar research on reliability and availability analysis of different types of energy systems and their hybrid forms could be

10 found in (Collins et al., 2009; Tian and Seifi, 2014; Zhao et al., 2017). To assist with the optimization of the design and 11 performance of energy systems, a method for thermoeconomic analysis of energy systems was presented in (Tsatsaronis, 12 1993). However, this technique did not take reliability into consideration during the analysis. Nagarajan,

13 Vijiyasamundiswary, Kumar (2013) have performed a reliability and cost analysis for optimising renewable energy 14 sources,

15 In this paper, we propose a novel method that can be used to predict the operational savings and costs of a WHRS via 16 thermodynamic and dependability analysis. Thermodynamic analysis throws light on savings and costs related to energy 17 utilisation. Dependability analysis shows the costs arising from system unavailability. The proposed approach builds on 18 recent advances in thermodynamic simulation and compositional dependability analysis techniques. It is a model-based 19 approach which employs component libraries and facilitates a high degree of automation. These properties in turn 20 simplify application of the method and its iterations. Using this approach, decision makers may perform swift studies of 21 different possible WHRS variants to select the best, i.e. the cost-optimal variant for installation.

22 Thermodynamic analysis exploits computational models of WHRS components which have been encoded using the 23 "Ship Energy Systems" library (Lampe and Freund, 2013; Freund et al., 2014) of SimulationX tool (ESI ITI GmbH, 24 2017), which is based on the Modelica language. The dependability analyses of WHRS variants are done using HiP25 HOPS (Hierarchically Performed Hazard Origin and Propagations Studies) (Papadopoulos et al., 2001, 2016). This is a 26 state-of-the-art, model-based technique in which a system model augmented with component failure data drawn from 27 libraries is used as basis for auto-calculation of system fault trees from which dependability is established. Energy 28 efficiency and dependability predictions are then translated to costs and overall economic performance of a WHRS. This 29 type of analysis can be used to compare different WHRS architectures. The proposed method is novel and efficient in 
1 application and iteration thanks to its model-based nature, the reusability and compositionality of the libraries used in the

2 analysis as well as the automated algorithms that can be run on the models.

3 In section 2, a number of possible configurations for WHRS is given. The key components of a WHRS system are

4 explained and a discussion follows on how they can be put together in a number of different candidate WHRS

5 architectures for evaluation. Section 3 proposes a method for analysis and selection of an optimal WHRS architecture.

6 The focus is on thermodynamic and dependability analysis of the architecture and the translation of results to savings

7 and costs arising assuming a specific operational scenario. Economic performance is ultimately used as criterion for

8 selection among a set of possible WHRS architectures. We show that the analysis of each architecture reuses

9 thermodynamic and failure models of more basic WHRS components. Section 4 focuses on thermodynamic and failure

10 modelling at component level where such reuse is possible. Section 5 applies the method to a set of different WHRS

11 architectures assuming a range of operational scenarios. Finally, in the light of results from the case study, in Section 6

12 conclusions are drawn.

\section{2. Architectures for WHRS}

14 Incorporating a WHRS leads to an increase of the ship's energy efficiency for significant main engine loads. Different

15 WHRS solutions are available for ship operations, and when designers choose one they consider a number of factors

16 which include engine power, electrical power demand, ratio of engine loads, available space in engine room, emissions

17 requirements and payback time (MAN Diesel \& Turbo, 2012).

\section{$18 \quad 2.1$ WHRS components}

19 Typically, the WHRS is run in parallel with a shaft generator and auxiliary generator sets to meet high electrical power

20 demands (Benvenuto et al., 2014; Benvenuto et al., 2014a; Dimopoulos et al., 2014). A large WHRS might meet the

21 total electrical power demand during standard operation even as a standalone energy source. This potentially avoids the

22 installation of an additional auxiliary diesel generator set thereby saving installation and running costs. A schematic

23 layout of a WHRS is displayed in Figure 1. We start from a discussion of key components of WHRS and proceed to

24 sketch how these components are put together to form some of the most common WHRS architectures. 


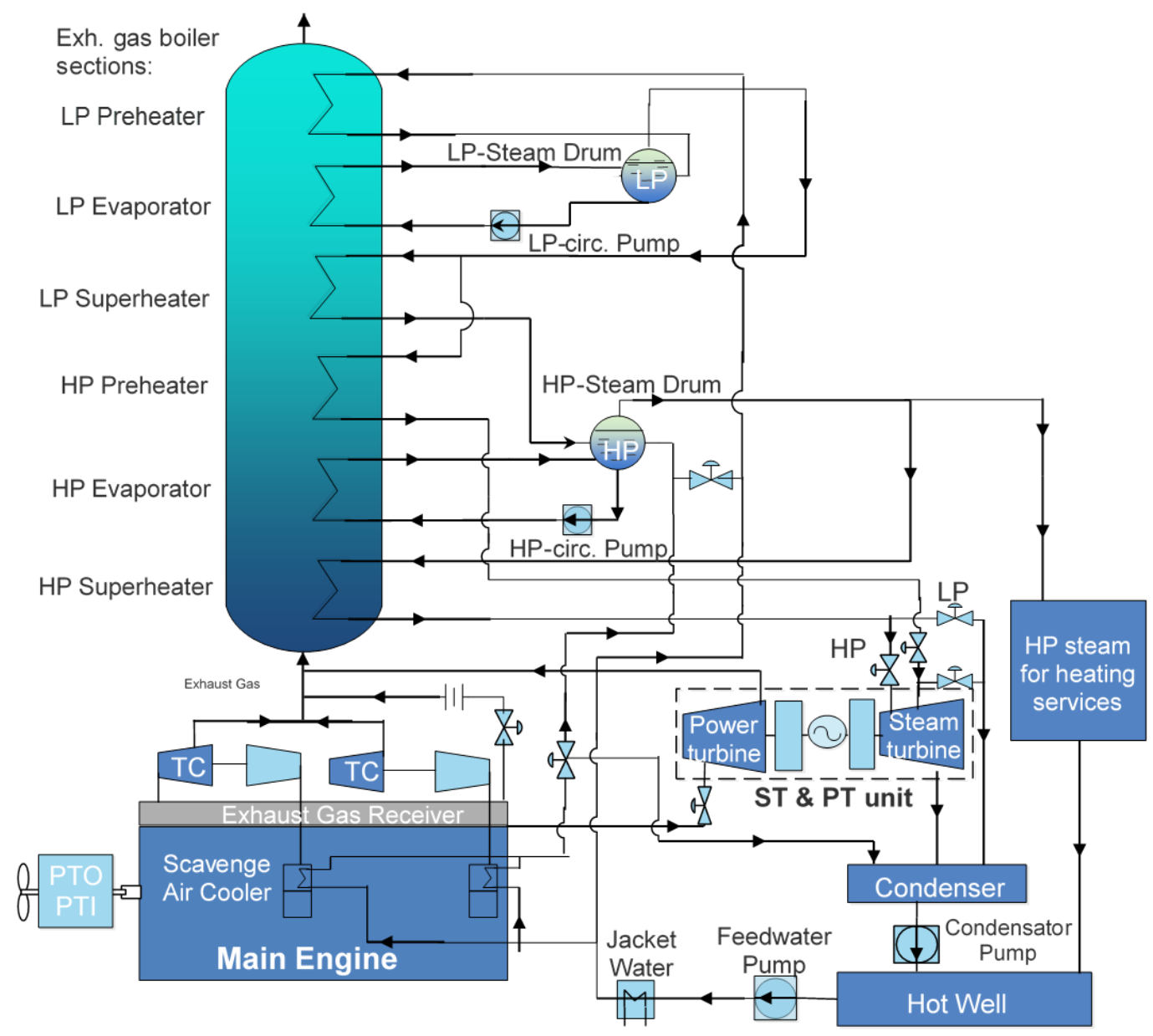

Figure 1: Schematic diagram of WHRS (MAN Diesel \& Turbo, 2012)

\section{Power Turbine $(\mathbf{P T})$}

2 The power turbine (PT) directly uses the exhaust gas of the main engine to drive a turbine. Therefore, up to $12 \%$ of the

3 exhaust gas flow bypasses the turbocharger (TC), driving the power turbine that, in turn, drives a generator, as shown in

4 the middle of Figure 1. The PT is connected to the generator via a gearbox. The PT operates between 50 and $100 \%$ of

5 the engine's maximum continuous rating (MCR). At engine loads less than 50\% MCR, the exhaust gas bypass feeding

6 the PT valve is closed.

\section{Heat Recovery Steam Generator (HRSG)}

8 The heat recovery steam generator consists of a heat exchanger which employs the high temperature of the main engine

9 exhaust gas to produce steam for running the steam turbine, which in turn drives a generator. The steam production can 10 be realized in several pressure levels, where each additional level increases the efficiency of the component. Single and 11 dual pressure HRSGs are the standard for maritime applications. The condenser, feed-water pump and steam drum are 12 all contained in the HRSG module. 
2 The steam turbine (ST) indirectly uses the exhaust gas of the main engine to drive a turbine. It takes advantage of the

3 high temperature of the exhaust gas via generation of steam by a single or dual level Heat Recovery Steam Generator

4 (HRSG), located in the upper left of the schematic diagram in Figure 1. The steam produced drives a single or dual

5 pressure level steam turbine, which further drives an electric generator through a gearbox. The steam turbine is turned on

6 at engine load levels above 35\% MCR. At lower engine loads the steam valve is closed and exhaust gas may bypass the

7 HRSG.

\section{Generator and Gearbox $(\mathbf{G})$}

9 A generator $(\mathrm{G})$ is required for transforming the rotational power of the turbines into electrical power. This is done via a 10 gearbox, due to the very high rotational speed of the turbines. A gearbox is required for each turbine since they are 11 running at different speeds.

\section{Shaft Motor (SM)}

13 Finally, a shaft motor (SM) is needed for properly covering the case where the WHRS generates more electrical power

14 than required. The shaft motor module converts the surplus electrical power into mechanical power additionally driving 15 the ship's propeller shaft and serving for propulsion. This typically is denoted as power take-in (PTI).

\section{$16 \quad 2.2$ Common WHRS architectures}

17 Components can be put together in a number of different WHRS which match better different operational profiles of a

18 vessel. The following three architectures serve as a basis for all the WHRS variants analysed in this paper.

\section{Architecture 1: Power Turbine, Gearbox, Generator and shaft motor (PT)}

20 The power turbine is the simplest and lower priced WHRS arrangement, see Figure 2. Up to 5\% of the generated power 21 (with respect to the main engine load) can be recovered - depending on the main engine size, its current load, as well as on the ratio of the exhaust gas bypassing the turbochargers (up to 12\%) and thereby driving the power turbine that, in turn, drives a generator, as shown in the middle of Figure 1. The power turbine (PT) operates between 50 and 100\% of the engine's maximum continuous rating (MCR). Note that the bypassed portion of exhaust gas for the PT is related to decreased turbocharger (TC) efficiency. This decreased turbocharger efficiency is regarded during modelling and simulation by considering a resulting increase in specific fuel oil consumption of the main engine, i.e. this is stated as $1.2 \%$ according to (MAN Diesel \& Turbo, 2012). At engine loads less than 50\% MCR, the exhaust gas bypass valve is closed, otherwise the efficiency of the TCs is not sufficiently high and a reliable operating point cannot be guaranteed. The expanded exhaust gas after passing the PT is added to the exhaust gas from the TC and lead back to the environment through the exhaust funnel (MAN Diesel \& Turbo, 2012; 2011). The PT is connected to a generator via a gearbox. 
1 Additionally to a WHRS, several diesel generator sets are installed on-board to satisfy the electrical demand. Usually a

2 low electrical power demand can be solely met by the PT system. When the power demand is larger, the WHRS is run in

3 parallel with one or more diesel generator sets.

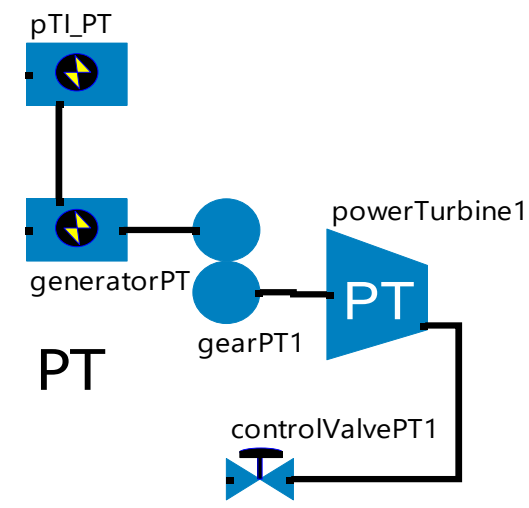

Figure 2: Model of power turbine WHRS

5 Architecture 2: Steam Turbine, HRSG, Gearbox, Generator and shaft motor (ST)

6 With a steam turbine generator layout, up to $8 \%$ of additional power (with respect to the main engine load) can be

7 recovered from the main engine exhaust gas. This WHRS architecture takes advantage of the high temperature of the

8 exhaust gas via generation of steam within a single or dual pressure level Heat Recovery Steam Generator (HRSG),

9 located in the upper left of the schematic diagram in Figure 1. The steam turbine is turned on at engine load levels above

$1035 \%$ MCR. The steam produced drives a single or dual pressure level steam turbine, which further drives an electric

11 generator through a gearbox to produce additional electric power. The inlet exhaust gas temperature for the HRSG is

12 higher if compared to that of an architecture with combined power and steam turbines. This is due to the absence of the

13 power turbine, i.e. here the part of the exhaust gas flow bypassing the TC is directly mixed with the exhaust outlet from

14 the turbocharger(s), see Figure 1. This increases the steam production and hence the resulting steam turbine power, see

15 also (MAN Diesel \& Turbo, 2012). In Figure 3, the corresponding model is shown with a single pressure level HRSG.

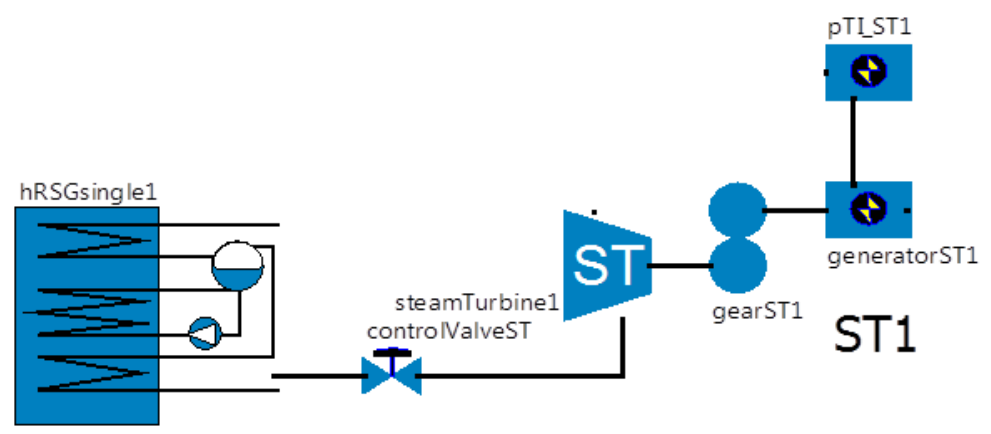




\section{Figure 3: Model of steam turbine WHRS}

\section{Architecture 3: Power turbine, Steam Turbine, HRSG, Gearbox, Generator and shaft motor (STPT)}

3 The system in Figure 1 shows a power turbine and a steam turbine driving a generator in parallel, which is suitable for

4 large electrical loads, e.g. for container vessels with a large number of reefers needed to be cooled down or cruise

5 vessels with high hoteling load. Up to $11 \%$ of additional power (with respect to the main engine load) can be recovered.

6 A typical STPT system layout is based on two stages. In the first stage, the exhaust gas, directly after the main engine,

7 passes through the power turbine and turbochargers, which are running in parallel. Then, after being mixed together they

8 enter the heat recovery steam generator as second stage. The HRSG can be implemented as a single or dual pressure

9 system and generating steam to drive one or two steam turbines. For low to medium electrical loads this solution is able

10 to cover the total electrical power supply, thereby considerably reducing fuel costs (MAN Diesel \& Turbo, 2012). In

11 Figure 4, the corresponding model is shown with a dual level HRSG.

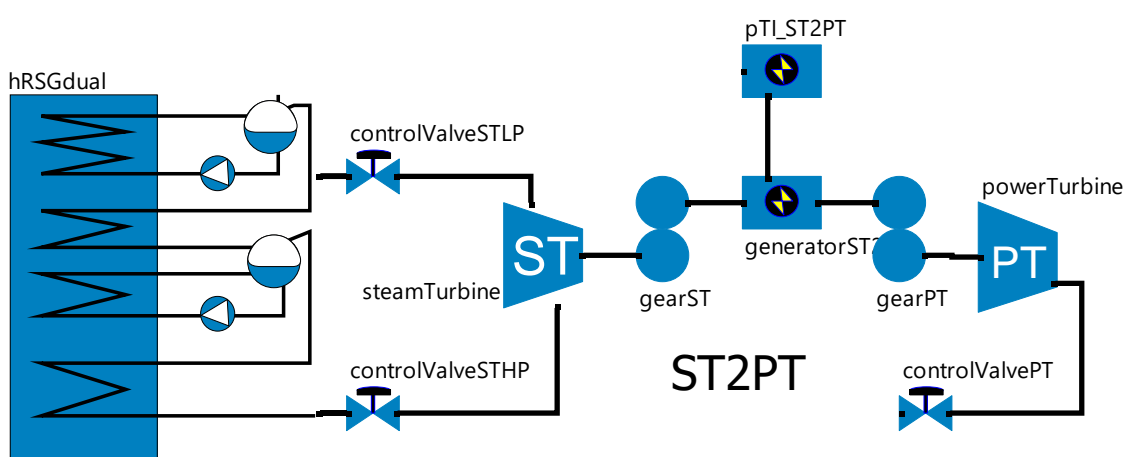

Figure 4: Model of power and steam turbine WHRS

12

\section{3. Method for analysis of impact of WHRS introduction}

14 The method proposed in the paper enables designers to choose a most suitable WHRS architecture for a given

15 operational scenario. Figure 5 gives a schematic overview of the method and shows that the inputs to the assessment of a 16 complete scenario are the ship particulars, operational profile, emission requirements and cost constraints. The method

17 consists of three steps: a) definition of the set of WHRS architectures to be investigated; b) energy and fault tree

18 computations, and c) an economic assessment done by translating the computations in (b) to costs and benefits. The

19 choice of a best architecture for the particular scenario is done by examining the result of the economic assessment. 

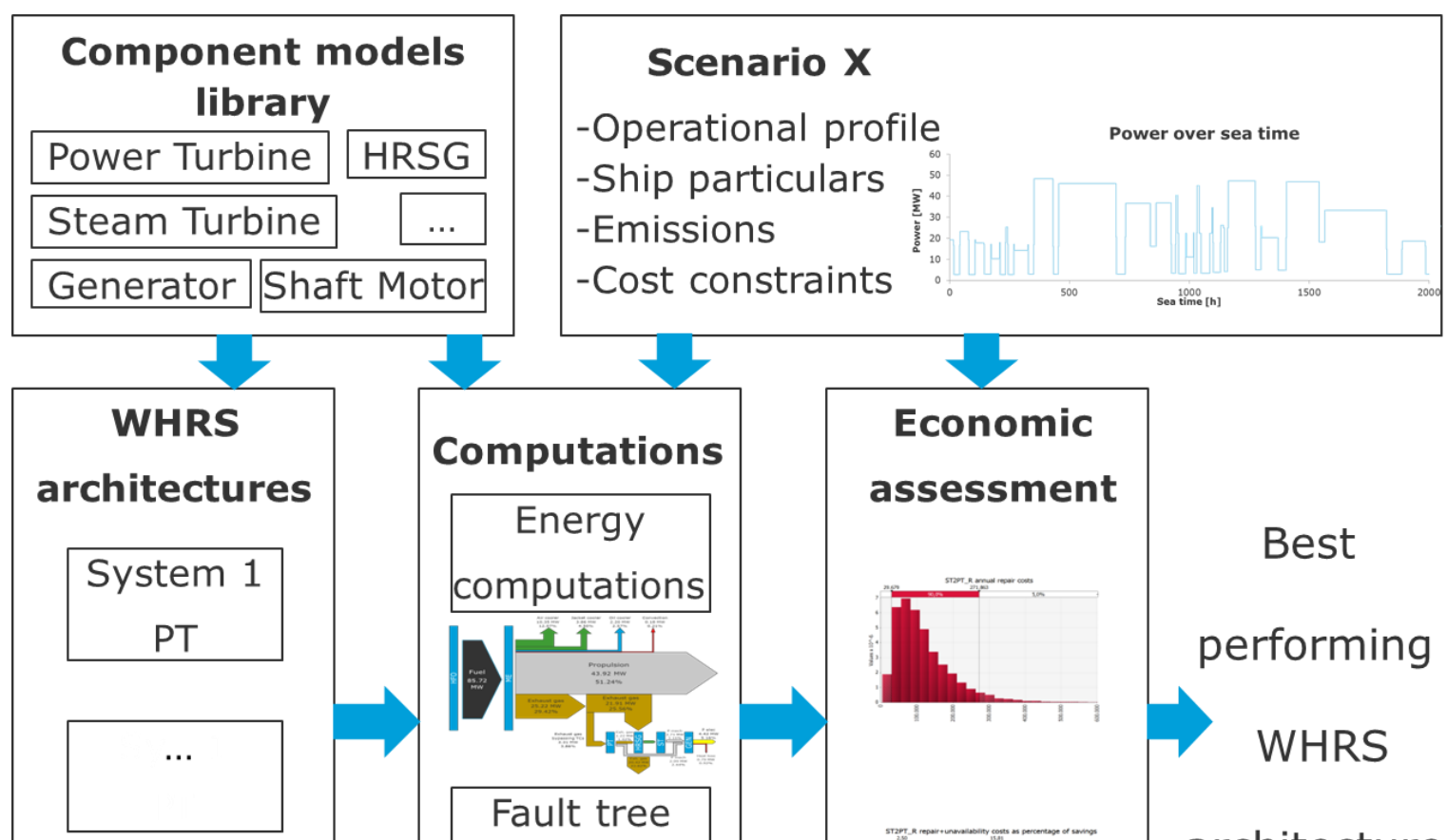

System i ST2PT

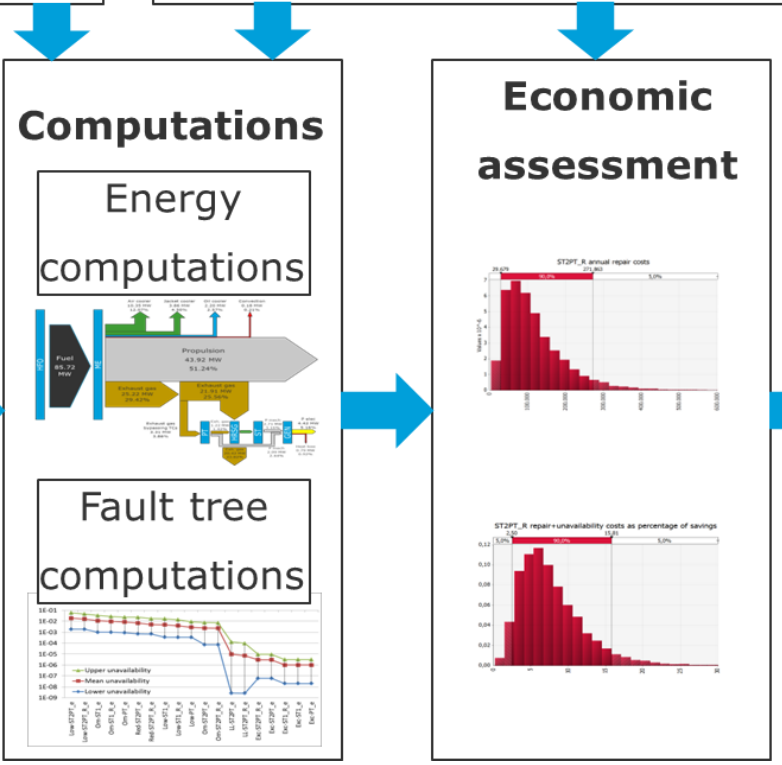

Best

performing

WHRS

architecture

Figure 5: Schematic overview of methodology

\section{$3 \quad 3.1$ WHRS architectures to be investigated}

4 The chosen set of WHRS designs includes the common types presented in subsection 2.2:

5 1. PT: Power Turbine, Gearbox, Generator and shaft motor

6 2. ST1: Steam Turbine, Gearbox, Generator, shaft motor and single level HRSG

7 3. ST2PT: Power turbine, Steam Turbine, Gearbox, Generator, shaft motor and dual pressure HRSG

8 Two variants with redundant water circulating pumps for the HRSG, ST1_R and ST2PT_R, have been added to this set

9 (Figure 6):

10 4. ST1_R: Steam Turbine, Gearbox, Generator, shaft motor and single pressure HRSG with redundant circulating

$11 \quad$ pumps

12 5. ST2PT_R: Power turbine, Steam Turbine, Gearbox, Generator, shaft motor and dual pressure HRSG with

13 redundant circulating pumps 

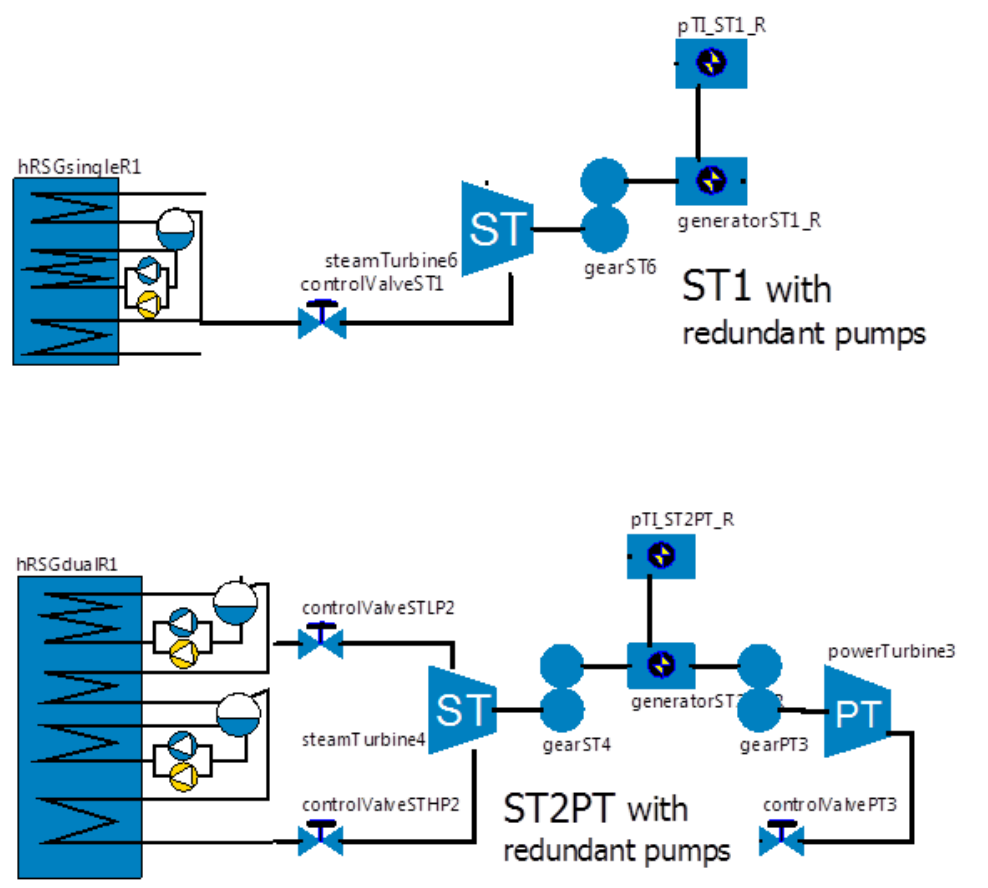

Figure 6: Model of steam turbine WHRS with redundant circulating pumps

2 The two architectures of Figure 6 are used to explore the effect of redundancies on the availability and economic

3 performance of WHRS, and allow a comparison with the equivalent basic designs of Figure 3 and Figure 4. The

4 redundancy implementation is such that one of the pumps operates while the other is in standby, i.e. in warm or cold

5 redundancy. For simplicity, pumps are identical, i.e. there is no differentiation of thermodynamic behaviour or failure

6 model. Moreover, the switching mechanism between the pumps is neglected. Circulating pumps were chosen for

7 replication given that they have high failures rates and low investment costs when compared to other components of the

8 WHRS. Note that in a similar way other architectures with a different choice of replication could have been defined at

9 this stage.

\section{$10 \quad 3.2$ Analysis of WHRS architectures}

11 After the definition of the set of applicable WHRS architectures, computations are performed. For each WHRS design,

12 an energy computation and corresponding dependability computation are carried out. Both computations use the same

13 system model, and each WHRS model is put together using reusable models of components and subsystems, as it is

14 depicted in the upper left corner of Figure 5.

\section{Energy computations}

16 The thermodynamic energy computations are carried out with the "Ship Energy Systems" library within SimulationX.

17 The software SimulationX is a multi-physics modelling and simulation tool based on the Modelica language, developed 
by ESI ITI (ESI ITI GmbH, 2017), and the Ship Energy Systems library is a joint development of ESI ITI and DNV GL

2 Maritime Advisory, Germany (Lampe and Freund, 2013; Freund et al., 2014).

3 The library was developed to simulate the main components of the vessel's machinery, with a focus on conversion of mechanical and electrical energy of the main and auxiliary systems. Engines and auxiliary systems can be modelled and calculated simultaneously regarding their operational profile, i.e., changing environmental conditions, engine operation profile and electrical demand. By enabling the reuse of components and subsystems, the Ship Energy Systems library can be efficiently employed for design and retrofitting analysis. The goal of the library is to model the energy conversion (thermodynamic, electric, mechanic) behaviour of the entire on-board energy system, including main and auxiliary engines, pumps, turbines and heat exchangers. Bialystocki and Konovessis (2016) have further statistically investigated

10 the effect of varying operational and environmental conditions on the energy efficiency. In principle, the results could be 11 employed as inputs for more refined energy computations, which was beyond the scope of the paper.

\section{Dependability analysis}

13 Dependability analysis is done using the Fault Tree Analysis (FTA) technique. In order to manage the complexity of the 14 analysis, we use a state-of-the-art compositional model-based dependability analysis tool, HiP-HOPS, which carries out 15 the analysis based on the same WHRS models used for the energy computations.

16 Fault Tree Analysis is one of the most prominent probabilistic risk assessment and system reliability analysis techniques.

17 FTA is a deductive or "top-down" analysis, which focuses on one particular undesired event, the "top event" or hazard, 18 and provides a method for logically determining causes of this event (Vesely et al., 2002). This is particularly useful for 19 systems with high complexity where the outcome of one or more combinations of noncritical events may produce an 20 undesirable critical event. FTA includes two aspects: a qualitative and a quantitative. Qualitative analysis is performed 21 by transforming fault trees into the minimal cut sets (MCSs). MCSs are the smallest combinations of basic events that 22 are necessary and sufficient to cause the top event. In a fault tree, a basic event is an initiating or basic fault that does not 23 require any further expansion. In quantitative analysis, the probability of the occurrence of the hazardous event or 24 system unavailability are mathematically calculated. System unavailability $Q(t)$ is the probability that the system is 25 down at time $t$ and the value of $Q(t)$ can be approximated using Esary Prochan method (Esary and Proschan, 1963) as 26 given by equation (1):

$27 \quad Q(t)=1-\prod_{i=1}^{n}\left(1-Q_{C S_{i}}(t)\right)$

28 Where $n$ is the number of independent cut sets and $Q_{C S_{i}}(t)$ is the unavailability of the cut set at time $t$. 
More details about the FTA is available in (Kabir, 2017). Conducting a fault tree analysis manually is rather time consuming and the quality of results is only as good as the validity of input data and accuracy of the fault tree logic (MIL-HDBK-338B, 1998). To overcome these challenges, the field of model-based dependability assessment (MBDA) (Joshi et al., 2006) has emerged, which simplifies dependability analysis process by automatically synthesising dependability related data from system models to generate dependability analysis artefacts such as fault trees. Over the years several tools and approaches, e.g., Failure Propagation and Transformation Notation (FPTN) (Fenelon and McDermid, 1993), Hierarchically Performed Hazard Origin and Propagation Studies (HiP-HOPS) (Papadopoulos et al., 2001), AltaRica (Arnold et al., 2000; Batteux et al., 2013), FSAP-NuSMV (Bozzano and Villafiorita, 2007), and the AADL with its error annex (Feiler and Rugina, 2007), have been developed to facilitate MBDA of complex systems. A review of these approaches could be found in (Aizpurua and Muxika, 2013). Loer and Harrison (2006) have presented a 11 model checking based method for the dependability analysis of interactive systems. In this paper, for the dependability analysis of WHRS architectures, we have used the HiP-HOPS technique. This technique was previously used for dependability analysis of complex engineering systems (Papadopoulos et al., 2011; Rüde et al., 2012).

14 All analysis and optimisation processes in HiP-HOPS are performed on an architectural system model which identifies material energy and data transactions among components. In this case the same model used for energy analysis is used for fault tree analysis. The first step in the analysis is the annotation of each component in the model with its local error logic. HiP-HOPS defines a language for the description of this error logic. The error logic of a component describes how it can fail and how it responds to failures that occur in other parts of the system. The error logic of a component can be specified as a list of internal failure modes of the component and a list of errors or deviations as they can be observed at component outputs. Each component failure mode is optionally accompanied by quantitative data, for example a failure and a repair rate. Output errors carry Boolean expressions which describe their causes as a logical combination of component faults and similar errors observed at component inputs. Input and output errors referenced in the error logic are described qualitatively and typically represent conditions such as 24 the omission (O) or commission (C) of parameters or qualitative deviations from correct value (i.e. hi-low) and expected timing behaviour (i.e. early-late). Collectively, a set of failure expressions that logically explain all possible errors at all output ports of a component provides a model of the error logic of the component under examination. This model can be stored in a library and could be re-used across different applications to simplify the manual part of the analysis and the overall application of the proposed technique. 
Once the model has been augmented with error logic, then computerised algorithms are used to automatically determine how errors propagate through connections in the model and cause hazardous functional failures at system outputs. Via the automated analysis algorithms of HiP-HOPS, it is thus possible to move from a local component view of failure to a global system view of failure captured in a set of fault trees. These show how the component failure modes representing the leaf nodes of the trees and their local effects logically combine and propagate through the system to cause functional failures that represent the top events of the fault trees. HiP-HOPS can perform qualitative cut-set analysis of fault trees. Quantitative analysis is also feasible when probabilistic parameters have been provided at component level, and is used to predict the failure probability, reliability, and availability of the system.

9 Energy simulation and FTA will have a disjoint set of model object parameters, but they share the same model topology.

10 FTA results can easily be kept up-to-date with changes in system design, as the analysis simply has to be repeated with

11 the updated system model. In addition, it is possible to analyse failure scenarios by simulation in order to determine the 12 impact of individual component failures on overall system performance. Also, simulation can provide insight to complex 13 scenarios such as temporal dependencies of failures, e.g. the failure scenario may become different depending on 14 whether failure mode A occurs before or after failure mode B. This is important in redundant or backup systems, where 15 a failure in the main system is only relevant if another failure has already put the backup system out of operation before. 16 Temporal dependencies are normally not covered by FTA tools; however, HiP-HOPS is able to consider them (Kabir et 17 al., 2017), and is able to examine them through simulation in a model-based approach (Troy, 2014). Magott and 18 Skrobanek (2012) have proposed an approach to perform temporal dependency analysis in fault trees.

\section{$19 \quad 3.3$ Economic analysis}

20 In the last step of the method, the energy and fault tree computations are evaluated within an economic analysis which

21 determines the WHRS selected. An example for an economic analysis in the context of assessing safety enhancing 22 measures can be found in (Guarin et. al, 2009).

23 All available information is used at this stage to estimate the potential fuel savings as well as costs related to the 24 determined unavailability. To connect energy computation results with the results from the dependability analysis both 25 sides are related to a monetary value as a common denominator. The determined energy efficiency of the WHRS can be 26 related to fuel oil savings, and thus costs savings; whereas failure probability is connected to monetary value via 27 occurring repair costs and the consequent unavailability can be connected to corresponding downtime costs. The latter 28 arise during periods the WHRS is not generating any power and, thus this missing amount of recovered energy has to be compensated by a diesel generator with related fuel costs. 
1 Wherever appropriate, calculations use probability density functions, either continuous for failure probability and unavailability or discrete as for operational profiles of main and auxiliary engines. The statistical evaluation is carried out with the “@Risk” tool, which performs Monte Carlo simulations (Palisade Corporation, 2015). This evaluation results in figures for savings, repair and unavailability that take into account the uncertainty in the failure data; and thus, are also given as probability density functions. These stochastic results can be used to obtain very robust estimates for important economic key parameters as average annual savings, annual repair costs, unavailability costs, and the average payback period considering unavailability and repair. Average fuel oil savings are based on the discrete probability distribution of the operational profile, thereby weighting the results from the thermodynamic analysis; but without considering unavailability or repair of components. Repair costs are computed by taking into account the continuous probability density functions for the estimated annual system failures, whereas unavailability costs are determined

11 regarding continuous probability density functions for the related system unavailability. Mean values of costs and savings are obtained by Monte-Carlo simulation. Finally, to determine the payback period including unavailability and

13 repair costs, the ratio of initial investment and the mean value of savings minus costs is calculated. These economic parameters represent the final result of this economic analysis, which can be used as decision support, for selecting the most suited WHRS architecture. Please note that the economic assessment could be refined by additionally determine the net present value and return on investment, which is not considered in this paper.

\section{4. Modelling of components and subsystems of WHRS}

18 The thermodynamic and failure models of WHRS components and subsystems that we have developed to underpin this 19 approach are presented in this section.

20 All WHRS examined in this paper have an electric generator connected through a gearbox either to a power turbine 21 (PT), to a steam turbine (ST1 and ST1_R) or to both (ST2PT and ST2PT_R). Dedicated control valves regulate the flow 22 through the exhaust gas and steam turbines. In case of the dual pressure HRSG within the ST2PT and ST2PT_R 23 arrangements the steam turbine has two steam inlets, respectively two control valves, one for high and one for low 24 pressure steam flow. The single pressure HRSG basically consists of a group of heat exchangers for pre-heating, evaporating and super-heating the steam, together with a steam drum and pumps. The fluid being heated is water/steam and thereby the exhaust gas from the main engine is being cooled down. The dual pressure HRSG has additional heat exchangers, pumps and steam drum for the high pressure steam circuit. Thereby the pre-heating step for the low pressure steam circuit is not delivered by the HRSG itself, but typically by the engine jacket water and scavenge air heat, which is not considered here for simplicity. Further components, like condensers and steam consumers are not included in the 
model, since they are not exclusive to the WHRS, i.e. a dedicated boiler with these components would produce the steam in the absence of a WHRS.

\subsection{Thermodynamic models}

\section{Power turbine}

5 Both turbine types, power and steam turbine, convert enthalpy of a gas to mechanical energy via a turbine, and then in a

6 subsequent step to electric energy via a generator. For each turbine, the fluid process is governed by the continuity

7 equation $\dot{m}_{\text {in }}=-\dot{m}_{\text {out }}=\dot{m}$ and by the first law of thermodynamics $\dot{m} \cdot\left(h_{\text {in }}-h_{\text {out }}\right)=\dot{L}-\dot{Q}$. For both turbine types,

8 the thermal energy loss $\dot{Q}$ during the process can be neglected, since it is orders of magnitude smaller compared to the

9 mechanical power $\dot{L}$. For the power turbine, the thermodynamics law can be rearranged to the following equation (2)

$10 \quad \dot{m}_{e} \cdot c_{p_{g}} \cdot\left(T_{e}^{\text {in }}-T_{e}^{\text {out }}\right) \cdot \eta_{m}=P_{m e c}^{P T}$,

11 where $c_{p_{g}}$ is the specific heat capacity of the exhaust gas flow, which is nearly constant over the applicable pressure and 12 temperature range, $\eta_{m}$ is the power turbine mechanical efficiency and $P_{m e c}^{P T}$ is the produced mechanical power. The 13 outlet temperature of the power turbine $T_{e}^{\text {out }}$ can be calculated by using the real expansion equation $T_{e}^{\text {out }} / T_{e}^{\text {in }}=1-$

$14 \eta_{P T} \cdot\left[1-\left(p_{e}^{\text {out }} / p_{e}^{\text {in }}\right)^{1-1 / \gamma_{e}}\right]$, where the outlet pressure $p_{e}^{\text {out }}$ is equal to the atmospheric pressure plus the pressure drop 15 in the funnel and/or in the HRSG (please refer to following paragraph). The isentropic turbine efficiency $\eta_{P T}$ takes into 16 account the non-isentropic gas expansion due to friction effects between the fluid and the mechanical blades.

17 A control valve (splitter) has been included within the STPT and PT components to regulate the operation of the power 18 turbine. In case of an engine load below 50\% MCR, the exhaust gas flow bypasses the PT and is directly added to the 19 exhaust gas after the TC, and then lead back to the environment through the exhaust funnel or HRSG, if provided.

20 The input parameters of the simulation model are the temperature $T_{e}^{i n}$, pressure $p_{e}^{i n}$ and mass flow $\dot{m}_{e}$. Internal 21 parameters are the power turbine efficiency $\eta_{P T}$ and specific heat ratio $\gamma_{e}$. Output parameters are the temperature $T_{e}^{\text {out }}$ 22 and power $P_{m e c}^{P T}$.

\section{HRSG}

24 A brief description of the dual-pressure level HRSG is given here, a detailed description can be found in the literature 25 (MAN Diesel \& Turbo, 2011; 2012; Rolls-Royce, 2010; Trucco, 2012; Wärtsilä, 2007; Al-Hobo and Salamah, 2013). In 26 Figure 7, a typical heat recovery diagram is shown for a dual-pressure level HRSG, i.e. displaying the temperature vs. 27 heat transmission for upstream and downstream. 


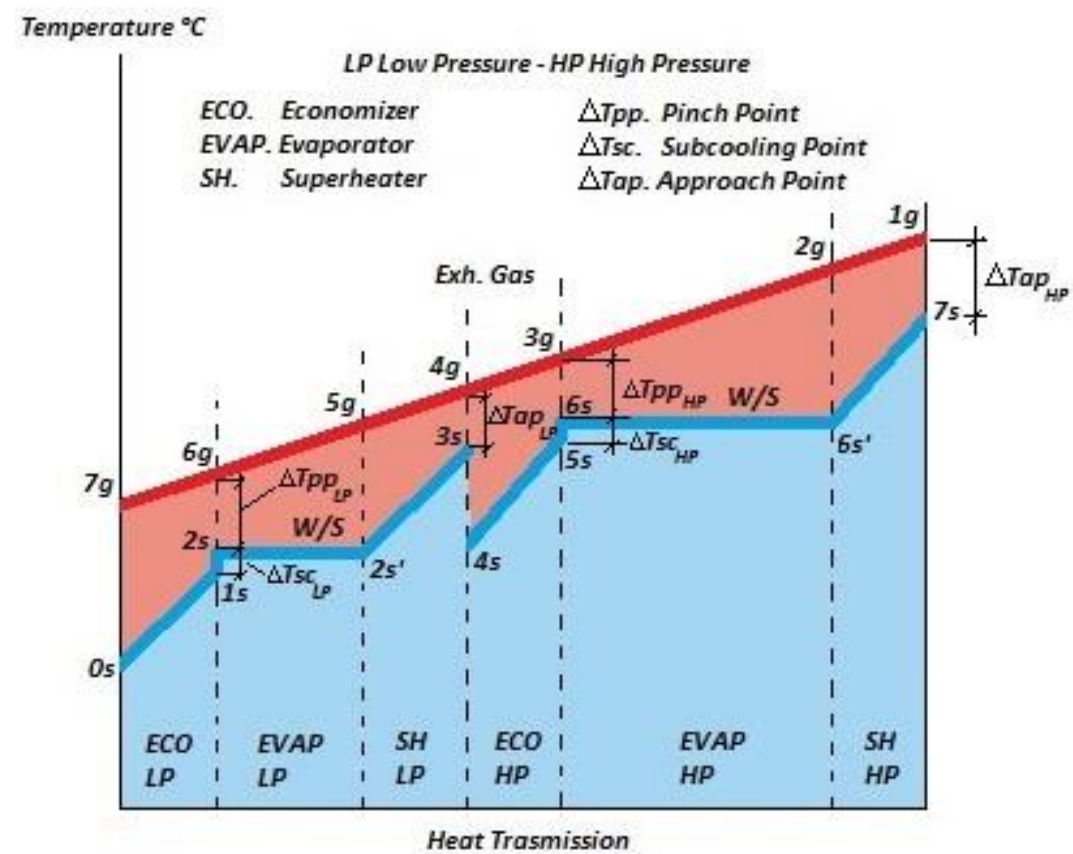

Figure 7: Qualitative heat transmission diagram for dual-pressure level HRSG (MAN Diesel \& Turbo, 2012)

2 For the design of an HRSG the area between the upper and lower curve plays a major role: it is a visualization of the

3 heat transfer characteristics of the steam generator. With ideal transfer efficiency, the temperatures of the fluids would coincide at either the left or right side of the diagram. The temperature difference on the left side of the diagram indicates the remaining energy in the exhaust gases, whereas the temperature difference at the right-hand side shows to what extent the steam was able to absorb the exhaust gas heat. Limiting factors in the heat exchanger efficiency are the exhaust gas outlet temperature that should be higher than the dew point of sulphuric acid to avoid corrosion, as well as material cost and component size: as the temperature difference between the fluids decreases, significantly more heat exchanger area is required.

10 The following two energy balances are implemented within the HRSG module, thereby using indexes as in Figure 7.

11 Firstly, the energy balance for the evaporator and the super-heater sections are given by

$13 \dot{Q}_{E V A P, S H}^{L P}=\dot{m}_{s} \cdot\left(\Delta h_{E V A P}^{L P}+\Delta h_{S H}^{L P}\right)=\dot{m}_{g} \cdot c_{p_{g}} \cdot\left(T_{4 g}-T_{6 g}\right) \cdot \eta_{H R S G}^{L P, E V+S H}$

14 Secondly, the energy balances of the economizer, which can be used for the evaluation of the temperature drop in this component:

$16 \quad \dot{Q}_{E C O}^{H P}=\dot{m}_{S} \cdot \Delta h_{E C O}^{H P}=\dot{m}_{g} \cdot c_{p_{g}} \cdot\left(T_{3 g}-T_{4 g}\right) \cdot \eta_{H R S G}^{H P, E C O}$ 
$1 \quad \dot{Q}_{E C O}^{L P}=\dot{m}_{s} \cdot \Delta h_{E C O}^{L P}=\dot{m}_{g} \cdot c_{p_{g}} \cdot\left(T_{6 g}-T_{7 g}\right) \cdot \eta_{H R S G}^{L P, E C O}$

2 The sum of the equations (3) - (6) yields the total amount of heat exchange in the HRSG:

$3 \dot{Q}_{H R S G}=\dot{Q}_{E C O}^{H P}+\dot{Q}_{E C O}^{L P}+\dot{Q}_{E V A P, S H}^{H P}+\dot{Q}_{E V A P, S H}^{L P}=\dot{m}_{g} \cdot c_{p_{g}} \cdot\left(T_{1 g}-T_{7 g}\right) \cdot \eta_{H R S G}$

4 The overall efficiency $\eta_{H R S G}$ of the HRSG is defined in equation (7); and is between the minimum and maximum value

5 of the subcomponent efficiency factors that are stated in the equations (3) - (6).

6 Analogous to the power turbine, a control valve (splitter) has been included within the HRSG components to regulate the

7 operation of the steam turbine. At engine loads below 35\% MCR the total exhaust gas flow bypasses the HRSG to avoid

8 any steam production, and is then directly sent to the funnel.

9 The input parameters of the simulation model in the exhaust gas side are the temperature $T_{1 g}$ and mass flow $\dot{m}_{g}$. The

10 output is the temperature $T_{7 \mathrm{~g}}$. On the steam production side, internal parameters are the condenser pressure $p_{\text {cond }}$ and

11 steam pressures $p_{s_{H P}}^{i n}, p_{s_{L P}}^{i n}$. Outputs are the mass flows $\dot{m}_{s_{H P}}, \dot{m}_{s_{L P}}$ and temperatures $T_{3 s}, T_{7 s}$. Internal HRSG

12 parameters are pinch points $\Delta T_{p p}^{H P}, \Delta T_{p p}^{L P}$, subcooling points $\Delta T_{s c}^{H P}, \Delta T_{s c}^{L P}$, approach points $\Delta T_{a p}^{H P}, \Delta T_{a p}^{L P}$ and the

13 efficiencies $\eta_{H R S G}^{H P, E V+S H}, \eta_{H R S G}^{L P, E V+S H}, \eta_{H R S G}^{H P, E C O}$ and $\eta_{H R S G}^{L P, E C O}$. The overall efficiency $\eta_{H R S G}$ can be calculated afterwards by

14 means of equation (7).

\section{Steam turbine}

16 The outlet temperature of the dual pressure steam turbine $T_{s}^{\text {out }}$ depends on the inlet condition, the expansion pressure

17 and the isentropic efficiency. The inlet condition of the steam turbine is calculated within the HRSG module (please

18 refer to paragraph above), based on the steam pressure $p_{s}^{\text {in }}$ and approach point temperature difference $\Delta T_{a p}$. The working

19 pressure of the condenser $p_{\text {cond }}$ (typically a vacuum) defines the expansion pressure of the turbine. In case of dual

20 pressure level ST, there exist two different steam inputs with different mass flows, inlet steam temperatures and

21 pressures (HP and LP).

22 For the calculation of the actual power the steam enthalpy downstream the turbines connected in series is considered

23 using the turbine isentropic efficiencies $\eta_{S T}^{H P}$ and $\eta_{S T}^{L P}$. The flow through the low pressure ST is considered as the mixture

24 of the high pressure outlet flow and the low pressure steam flow from the HRSG. Thus, for the corresponding enthalpies

25 the equations (8) - (10) hold:

$26 \quad h_{s_{H P}}^{\text {out }}=h_{s_{H P}}^{\text {in }}-\left(h_{s_{H P}}^{\text {in }}-h_{s_{H P}}^{\text {ise }}\right) \cdot \eta_{S T}^{H P}$,

$27 h_{s_{M I X}}^{\text {in }}=\left(\dot{m}_{s_{H P}} \cdot h_{s_{H P}}^{\text {out }}+\dot{m}_{s_{L P}} \cdot h_{s_{H P}}^{\text {in }}\right) /\left(\dot{m}_{s_{H P}}+\dot{m}_{s_{L P}}\right)$, 
$1 \quad h_{s_{L P}}^{\text {out }}=h_{s_{M I X}}^{\text {in }}-\left(h_{s_{M I X}}^{\text {in }}-h_{s_{L P}}^{\text {ise }}\right) \cdot \eta_{S T}^{L P}$.

2 Hence, the mechanical power produced by the dual pressure ST is given in equation (11), i.e. by the sum of the

3 corresponding HP and LP turbine contributions:

$4 \quad P_{m e c}^{S T}=\left(\dot{m}_{s_{H P}}+\dot{m}_{s_{L P}}\right) \cdot\left(h_{s_{M I X}}^{\text {in }}-h_{s_{L P}}^{\text {out }}\right) \cdot \eta_{m e c}^{S T, L P}+\dot{m}_{s_{H P}} \cdot\left(h_{s_{H P}}^{\text {in }}-h_{s_{H P}}^{\text {out }}\right) \cdot \eta_{m e c}^{S T, H P}$.

5 The inputs of the simulation model are temperatures $T_{s_{H P}}^{i n}, T_{s_{L P}}^{i n}$, pressures $p_{s_{H P}}^{\text {in }}, p_{s_{L P}}^{\text {in }}$ and mass flows $\dot{m}_{s_{H P}}, \dot{m}_{s_{L P}}$.

6 Internal parameters are the steam turbine efficiencies $\eta_{S T}^{H P}, \eta_{S T}^{L P}, \eta_{m e c}^{S T, L P}$ and $\eta_{m e c}^{S T, H P}$. Outputs are the temperature $T_{S}^{\text {out }}$ and

7 power $P_{m e c}^{S T}$. For a more sophisticated nonlinear mathematical steam turbine models, including validation of simulation

8 results by measurements, please refer to (Chaibakhsh and Ghaffari 2008).

\section{Generator and Gearbox}

10 The generator module converts the rotational power of the turbine into electric power. It is required in all WHRS

11 designs. In the STPT module, the steam and power turbines are both connected to a common generator via reduction

12 gearboxes. The outlet electrical power is evaluated in equation (12) via the efficiency of gearbox and generator:

$13 P_{e l}=\eta_{\text {gear }} \cdot \eta_{\text {gen }} \cdot\left(P_{m e c}^{P T}+P_{m e c}^{S T}\right)$.

14 The input parameters of the combined STPT simulation model are $P_{m e c}^{P T}, P_{m e c}^{S T}$. Internal parameters are the gearbox and 15 generator efficiency $\eta_{\text {gear }}$ and $\eta_{\text {gen }}$. Output is the electrical power $P_{e l}$ produced.

\section{Shaft motor}

17 The shaft motor module converts the surplus electrical power $P_{e l}^{\text {extra }}$ into mechanical power $P_{S M}$ through $\eta_{S M}$, the shaft 18 motor efficiency: $P_{S M}=\eta_{S M} \cdot P_{e l}^{\text {extra }}$.

19 Thus, the final main engine load $P_{M E}$ is the difference of the required main engine power $P_{M E}^{r e q}$ for meeting the vessel 20 speed requirement and the shaft motor power: $P_{M E}=P_{M E}^{r e q}-P_{S M}$.

21 In principle, the shaft motor can also be driven by the diesel engines and then either run alone (standby or waiting in 22 harbour) or together with the main engine for serving peak loads (Rolls-Royce, 2010). Often the shaft motor can be 23 operated in the reverse direction, i.e. as shaft generator, thereby potentially avoiding the use of one or more DG sets.

24 These basic variants of WHRS were encoded in the SimulationX tool and they were integrated into larger simulation 25 models to assess their different effects on the energy efficiency of a ship. Preliminary work on this modelling can be 26 found in (Ginnetti et al., 2015). 
The WHRS variants that were analysed in this paper are shown in Figure 2 to Figure 4 and Figure 6. As explained in section 3.2, HiP-HOPS analysis requires the development of a library of local failure models for the components that compose these architectures. Figure 8 shows an example, in this case the failure model of the generator of the WHRS with respective interfaces for the connections to other components. The failure behaviours are given in the form of equations with Boolean expressions. These equations define the output deviations dependent on input deviations and/or internal failure modes. All output deviations, located on the left hand side of the equations are highlighted in bold letters.

8 On the right hand side the source of the output deviation is defined, i.e. as combinations of input deviations or (local)

9 internal component failure modes, the last highlighted in italic letters.

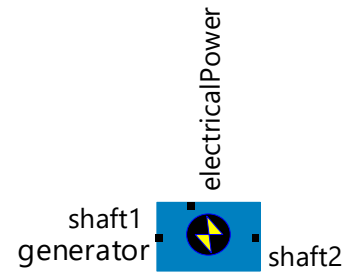

Figure 8: Model of generator in STPT architectures

10

11 Exc-electricalPower $=$ Exc-shaft1 or Exc-shaft2

12 Red-electricalPower $=$ Low-shaft 1 or Low-shaft 2

13 Low-electricalPower $=($ Low-shaft1 and Low-shaft2 $)$ or Om-shaft1 or Om-shaft2 or Degraded

14 LowLow-electricalPower $=($ Degraded and Low-shaft 1$)$ or $($ Degraded and Low-shaft2 $)$

15 Om-electricalPower $=(\mathrm{Om}$-shaft1 and Om-shaft2) or Critical or (Degraded and Low-shaft1 and Low-shaft2)

16 Here, the deviation classes of the generator model for the combined ST and PT arrangements are discussed in the

17 following. The generator model has three interfaces: "shaft1", "shaft2" (one for each turbine) and "electricalPower", as

18 shown in Figure 8, as well as two internal failure modes: "Degraded" and "Critical". We define five possible output

19 deviations in its "electricalPower" interface listed below Figure 8, depending on the level of the output after failure. The

20 definition of these deviations depends on the needs of the modeller, thus, can be adjusted to the required level of detail

21 and differentiation of cases. These five functional output deviations are also applied for all the other investigated WHRS

22 component models. They are abbreviated and generically defined as follows, see also Figure 9:

- Exc: Excess level of (power) output, i.e. above $100 \%$ of nominal or maximal expected output.

- $\quad$ Red: Reduced level of (power) output, expected output power is less than $100 \%$, down to $75 \%$. 
- Low: Low level of (power) output, lower than in above case "Red", expected output power is less than 75\%, down to $25 \%$.

- LowLow: Very low level of (power) output, lower than in above case "Low", expected output power is less than $25 \%$, down to almost $0 \%$.

- Om: Omission of (power) output, expected output power $0 \%$.

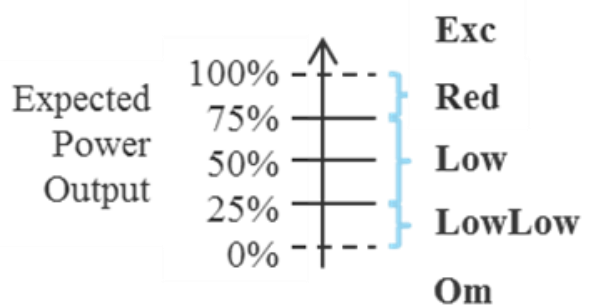

Figure 9: Output deviation classes of WHRS

6 The first output deviation of the generator is the excess of output power (Exc-electricalPower). The right-hand side of

7 the equation describes the potential sources for the output deviation, here either an excess of power input in shaft1 (Exc-

8 shaft1), or an excess of power input in shaft2 (Exc-shaft2) could cause excess of output power from the generator.

9 Reduced output (Red-electricalPower) is caused if one of shaft1 or shaft2 has a low input. The output deviation low

10 power (Low-electricalPower) is present if both shaft 1 and shaft2 deliver a low input power, or if one side fails to deliver

11 power (Om-shaft1 OR Om-shaft2), or, finally, if the generator itself is Degraded. The output deviation of very low

12 power (LowLow-electricalPower) occurs if a combination of the events of a generator failure mode Degraded and one

13 input deviation Low of either shaft occur simultaneously (Degraded AND Low-shaft1) or (Degraded AND Low-shaft2).

14 Finally, the output deviation of no power output (Om-electricalPower) applies if either both shafts have an omission of

15 input (Om-shaft1 AND Om-shaft2), or the generator is Critical, or, if there is a combination of the generator failure

16 mode Degraded and both shafts have a low input power (Degraded AND Low-shaft1 AND Low-shaft2).

17 The above description of the modelled failure behaviour shows one advantage of applying FTA in a model-based

18 approach, i.e. the easy consideration of combination of failure modes with lower criticality which, if occurring together,

19 could lead to a critical event at system level. The combinations may seem to be simple at component level, but when

20 these components are put together to a complex system, it is not trivial to consider correctly all possible combinations.

21 After annotating the different WHRS components and arrangements, one should define a hazardous top event, i.e. the

22 system output deviation for which a fault tree will be generated. Here, two top events are chosen, first the generator

23 output at its electric power which covers most of the practical cases. As a second top event, the output of the shaft motor, 
also denoted as Power Take In (PTI), is chosen, which additionally covers the cases where the produced electrical power

2 is larger than the actual demand. Note that for all considered WHRS the second top event is equivalent to the output of

3 an OR gate with the PTI component and the first top event as inputs.

4 In the analysis, all output deviation classes, i.e. Exc, Red, Low, LowLow and Om (see Figure 9), are considered as 5 possible system outputs. Thus, all of them are selected as respective fault tree events, and thereby the probability is

6 determined that a WHRS arrangement deviates from its expected operation. For the WHRS components, the failure data

7 from OREDA (2009) was taken as reference. Failure data for WHRS components was not available, thus, the values

8 used are an approximation. However, we note that this data is used only for relative comparison between similar

9 systems, and hence the accuracy of these values is less critical than in the case of absolute and accurate prediction. When

10 data for a component was not available, the failure data from a comparable similar component was chosen. In Table 1,

11 the main WHRS components, their failure modes, respective failure rates and Mean Times To Repair (MTTR) are listed.

12 Thereby, Critical means that the component cannot deliver the intended output, whereas Degraded means that the output

13 is reduced. The abbreviations used in the description of the failure modes are HE for heat exchanger, HP for high

14 pressure and LP for low pressure.

15 Table 1: Component failure modes, failure rates and Mean Time To Repair (OREDA, 2009)

\begin{tabular}{|c|c|c|c|}
\hline Component & Failure Modes & Failure Rates $\left(\mathbf{h}^{-1}\right)$ & MTTR (h) \\
\hline \multirow{2}{*}{ Generator } & Degraded & $58.72 \mathrm{E}-6$ & 24 \\
\hline & $\overline{\text { Critical }}$ & $76.19 \mathrm{E}-6$ & 30 \\
\hline \multirow{2}{*}{ Gearbox } & Degraded & $10.00 \mathrm{E}-6$ & 20 \\
\hline & Critical & $8.70 \mathrm{E}-6$ & 25 \\
\hline \multirow{2}{*}{ Power Turbine } & Degraded & 103.39E-6 & 12 \\
\hline & $\overline{C r i t i c a l}$ & $54.35 \mathrm{E}-6$ & 113 \\
\hline \multirow{2}{*}{ Steam Turbine } & Degraded & 103.39E-6 & 12 \\
\hline & Critical & 54.35E-6 & 113 \\
\hline \multirow{11}{*}{$\begin{array}{l}\text { Heat Recovery Steam } \\
\text { Generator, Dual Steam } \\
\text { Pressure }\end{array}$} & HPHEdegraded & \multirow{2}{*}{$36.50 \mathrm{E}-6$} & \multirow{2}{*}{24} \\
\hline & LPHEdegraded & & \\
\hline & HPHEcritical & \multirow{2}{*}{$13.98 \mathrm{E}-6$} & \multirow{2}{*}{72} \\
\hline & LPHEcritical & & \\
\hline & HPdrumDegraded & \multirow{2}{*}{$27.39 \mathrm{E}-6$} & \multirow{2}{*}{8} \\
\hline & LPdrumDegraded & & \\
\hline & HPdrumCritical & \multirow{2}{*}{$13.09 \mathrm{E}-6$} & \multirow{2}{*}{12} \\
\hline & $\overline{\text { LPdrumCritical }}$ & & \\
\hline & HPpumpDegraded & \multirow{2}{*}{ 114.16E-6 } & \multirow{2}{*}{8} \\
\hline & $\overline{\text { LPpumpDegraded }}$ & & \\
\hline & НРритр Critical & $86.51 \mathrm{E}-6$ & 18 \\
\hline
\end{tabular}




\begin{tabular}{llrr}
\hline Component & Failure Modes & Failure Rates $\left(\mathbf{h}^{-\mathbf{1}}\right)$ & MTTR (h) \\
\hline & LPpumpCritical & & \\
\hline \multirow{2}{*}{ Control Valve } & FailToClose & $0.50 \mathrm{E}-6$ & 2 \\
\cline { 2 - 4 } & FailToRegulate & $1.51 \mathrm{E}-6$ & 3 \\
\cline { 2 - 4 } FailToOpen & $1.01 \mathrm{E}-6$ & 2 \\
\hline \multirow{3}{*}{$\begin{array}{l}\text { Heat Recovery Steam } \\
\text { Generator, Single Steam }\end{array}$} & HEdegraded & $36.50 \mathrm{E}-6$ & 24 \\
\cline { 2 - 4 } & HEcritical & $13.98 \mathrm{E}-6$ & 72 \\
\cline { 2 - 4 } & DrumDegraded & $27.39 \mathrm{E}-6$ & 8 \\
\cline { 2 - 4 } & DrumCritical & $13.09 \mathrm{E}-6$ & 12 \\
\cline { 2 - 4 } PTI & Pumpegraded & $114.16 \mathrm{E}-6$ & 8 \\
\hline & PumpCritical & $56.51 \mathrm{E}-6$ & 18 \\
\hline & Degraded & $58.72 \mathrm{E}-6$ & 24 \\
\hline
\end{tabular}

\section{5. Case study}

3 This section contains the results of the simulation of different on-board energy recovery systems. The focus is on the

4 potential benefits of a WHRS in terms of fuel consumption, possible downtimes and costs. In subsection 5.1, the thermodynamic results are presented for the set of WHRS defined in subsection 3.1 and are compared to a baseline scenario of a ship energy system without any WHRS. In subsection 5.2, the results of the corresponding dependability analysis are presented and discussed. Finally, in subsection 5.3, the results of the economic analysis are given for all investigated systems.

\section{5.1 Thermodynamic simulation}

10 The simulation models contain the following components:

- Main engine and diesel generators

- Engine operating profile and electrical usage profile

- Power management system and power splitter

- Engine load sensor (for control valves)

19 Within the Ship Energy Systems library it is further possible to simulate the freshwater and seawater cooling circuit for main and auxiliary engines as well as the engine room fan providing cooling and charge air from the environment. For

- Shaft motor and fuel tank

- Operating/environmental conditions

- One of three variants of WHRS: ST2PT with dual pressure HRSG (in subsection 5.1.1), ST1 with single pressure HRSG (in subsection 5.1.2) and PT (in subsection 5.1.3)

the simulations provided in this paper, these systems are not explicitly implemented within the models but their effect is 
taken into account within the electrical usage profile, i.e. as required electrical power by pumps and fan (Freund et al., 2014). Based on the specific fuel oil consumption (SFOC) curves of each engine, the fuel tank component monitors the fuel consumption and calculates the fuel costs of the different WHRS. These can be used to calculate the payback period for the ship owner and/or charterer. Note that for suitable dimensioning of a WHRS the required space for all waste heat recovery components in the engine room has to be taken into account, which was not within the scope of this paper.

6 For the case study a large containership is considered, operating 330 days per year between Rotterdam and Buenos Aires. The vessel is equipped with a large two-stroke main engine with 54,900 kW MCR, three diesel generators with 2,000 kW each and one with $1500 \mathrm{~kW}$ for electrical power supply and a WHRS. The main engine uses heavy fuel oil (HFO) at a price of $300 \mathrm{USD} / \mathrm{ton}$, while the diesel generators use marine diesel oil (MDO) at a price of $450 \mathrm{USD} / \mathrm{ton}$.

10 The bunker prices are taken from Bunkerworld (2017) as roughly the lower bound of the varying average bunker prices 11 within 2017, i.e. between 2017/01-2017/09. Corresponding operating conditions are listed in Table 2. The large ratio of $1280 \%$ ME load indicates that this is a large newbuild containership, i.e. with adapted total installed MCR such that the 13 design condition really matches the actual reduced speed requirements. The large electrical power demand during 14 normal seagoing, slow steaming and manoeuvring is due to the large number of reefer containers onboard. The 15 considered air temperature varies between 10 and $30^{\circ} \mathrm{C}$, sea water temperature between 15 and $25{ }^{\circ} \mathrm{C}$ and the ambient 16 pressure between 990 mbar and 1020 mbar. The choice of parameters for efficiencies values, temperatures of the HRSG, 17 power and pressure levels of the turbines used in the simulation are assumptions based on typical values, mentioned by 18 experienced ship operation experts, but not a particular case. The efficiency values $\eta_{H R S G}^{L P, E V+S H}, \eta_{H R S G}^{H P, E V+S H}, \eta_{H R S G}^{L P, E C O}$,

$19 \eta_{H R S G}^{H P, E C O}$ of the HRSG are all set to 0.98 , whereas temperature differences of pinch, approach and subcooling points are 20 assumed as $\Delta T_{p p_{L P}}=\Delta T_{p p_{H P}}=20 \mathrm{~K}, \Delta T_{a p_{L P}}=\Delta T_{a p_{H P}}=15 \mathrm{~K}$ and $\Delta T_{s c_{L P}}=\Delta T_{s c_{H P}}=10 \mathrm{~K}$. Power turbine efficiency

21 is set to $\eta_{P T}=0.8$, and steam turbine mechanical and isentropic efficiencies are considered as $\eta_{\text {mec }}^{S T, L P}=\eta_{\text {mec }}^{S T, H P}=0.99$ 22 and $\eta_{S T}^{L P}=\eta_{S T}^{H P}=0.7$. Gearbox and generator efficiency are regarded as $\eta_{\text {gear }}=0.98$ and $\eta_{\text {gen }}=0.95$ respectively.

23 In Table 3, the simulation results for the baseline scenario of a ship energy system without a WHRS are displayed.

24 Table 2: Operating Conditions

\begin{tabular}{lrrrrr}
\hline \multirow{2}{*}{ Operating conditions } & \multicolumn{2}{c}{ Time } & \multicolumn{2}{c}{ Propulsion } & \multirow{2}{*}{$\begin{array}{c}\text { Electrical } \\
\text { power }(\mathrm{kW})\end{array}$} \\
\cline { 2 - 5 } & Ratio (\%) & Hours(h) & ME Load (\%) & Power (kW) & 5,000 \\
\hline Sea passage & 40 & 3,168 & 80 & 43,920 & 2,200 \\
\hline Ballast & 20 & 1,584 & 60 & 32,940 & 4,500 \\
\hline Slow steaming & 25 & 1,980 & 20 & 10,980 & 5,500 \\
\hline Manoeuvre & 5 & 396 & 0 & 0 & 3,200 \\
\hline Port & 10 & 792 & & 21,960 & 5 \\
\hline
\end{tabular}


2 Table 3: Simulation results large container - no WHR

\begin{tabular}{lrrrr}
\hline & \multicolumn{2}{c}{ Main Engine } & \multicolumn{2}{c}{ Diesel generators } \\
\cline { 2 - 5 } & $P_{M E}(\mathrm{~kW})$ & HFO $(\mathrm{t} / \mathrm{h})$ & $P_{D G s}(\mathrm{~kW})$ & MDO $(\mathrm{t} / \mathrm{h})$ \\
\hline Sea passage & 43,920 & 7.24 & 5,000 & 1.06 \\
\hline Ballast & 32,940 & 5.40 & 2,200 & 0.48 \\
\hline Slow steaming & 21,960 & 3.72 & 4,500 & 0.94 \\
\hline Manoeuvre & 10,980 & 1.95 & 5,500 & 1.15 \\
\hline Port & 0 & 0 & 3,200 & 0.70 \\
\hline
\end{tabular}

\subsubsection{Large container with ST2PT}

4 The first example considers the WHRS as dual-pressure level HRSG and STPT, as shown in Figure 10.

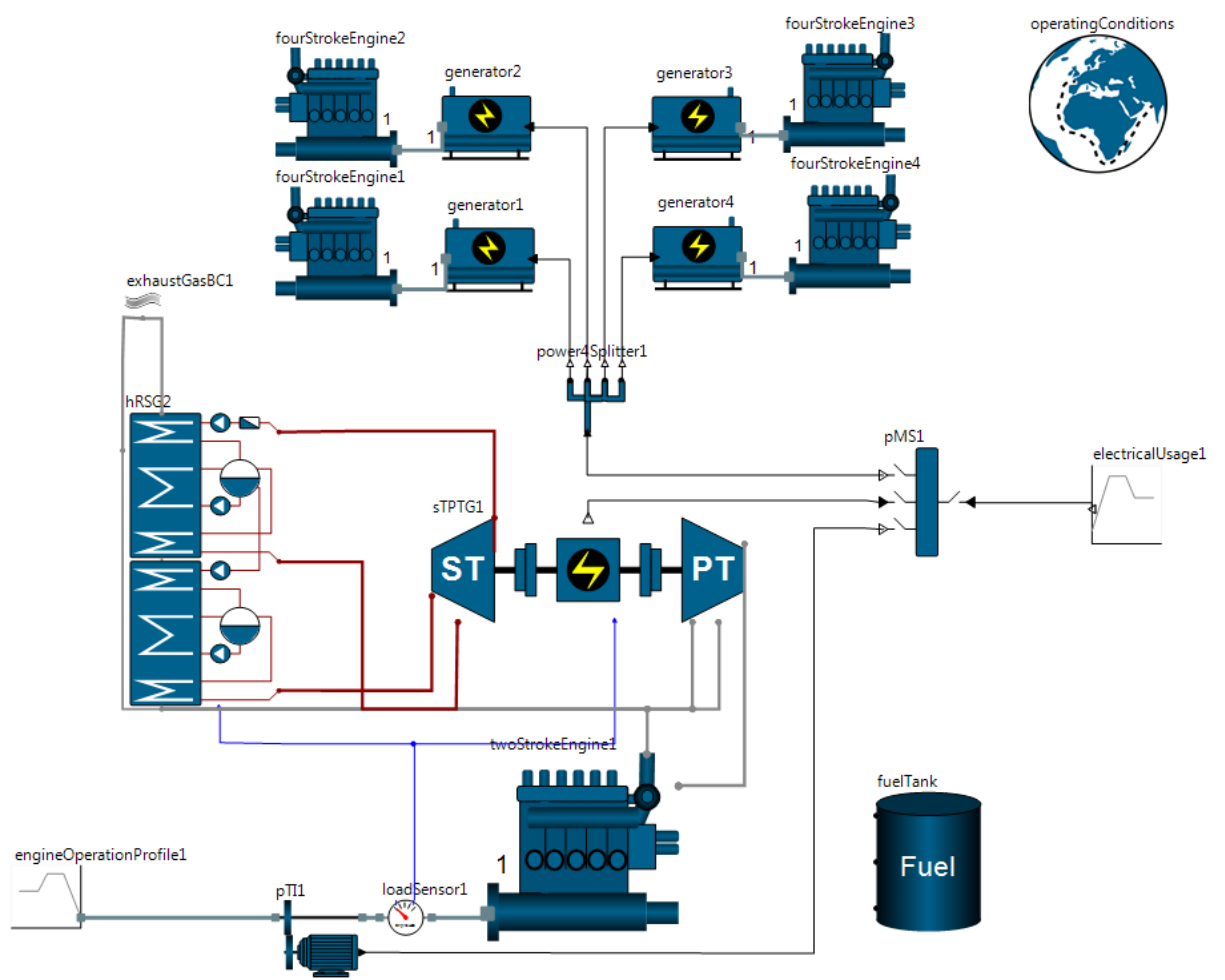

Figure 10: Case study simulation model with ST2PT

5

This WHRS solution is able to recover the largest amount of energy from all considered arrangements. Table 4 shows the results of the simulation in case of the ST2PT WHRS, where a $2 \mathrm{MW}$ power turbine and a $2.5 \mathrm{MW}$ steam turbine are considered. The power of the shaft motor is rated at $1 \mathrm{MW}$. Table 4 shows that during slow steaming the exhaust gas flow of the main engine bypasses the PT but the ST is running and produces electrical power. In case of ballast conditions, the electrical demand is totally covered by the WHRS, and the surplus generated power is used via the shaft motor to support propulsion, decreasing the requested engine load for fulfilling the propulsion requirements. This leads to additional main engine fuel savings. In the sea passage condition power- and steam turbine are running but due to the 
large electrical demand by the reefers, the auxiliary engines are running in part load as well. Manoeuvring and port stay modes are not displayed in Table 4, since no difference compared to the baseline case exists.

Table 4: Simulation results large container - ST2PT

\begin{tabular}{|c|c|c|c|c|}
\hline & & Sea passage & Ballast & Slow steaming \\
\hline \multirow{5}{*}{ HRSG } & $\dot{m}_{g}(\mathrm{~kg} / \mathrm{s})$ & 102.34 & 79.89 & 57.26 \\
\hline & $T_{g}^{\text {out }}\left({ }^{\circ} \mathrm{C}\right)$ & 161.44 & 161.48 & 161.63 \\
\hline & $p_{\text {cond }}(\mathrm{bar})$ & 0.05 & 0.05 & 0.05 \\
\hline & $p_{S_{-} L P}(\mathrm{bar})$ & 4.50 & 4.50 & 4.50 \\
\hline & $p_{S_{-} H P}($ bar $)$ & 10 & 10 & 10 \\
\hline \multirow{5}{*}{ ST } & $\dot{\mathrm{m}}_{\mathrm{s}_{-} \mathrm{LP}}(\mathrm{kg} / \mathrm{s})$ & 1.49 & 1.15 & 0.81 \\
\hline & $\dot{\mathrm{m}}_{\mathrm{s} \_\mathrm{HP}}(\mathrm{kg} / \mathrm{s})$ & 2.82 & 2.37 & 2.18 \\
\hline & $\mathrm{T}_{\mathrm{S}_{-} \mathrm{LP}}^{\mathrm{in}}\left({ }^{\circ} \mathrm{C}\right)$ & 182.52 & 182.34 & 181.63 \\
\hline & $\mathrm{T}_{\mathrm{S}_{-} \mathrm{HP}}^{\mathrm{in}}\left({ }^{\circ} \mathrm{C}\right)$ & 239.23 & 243.61 & 261.49 \\
\hline & $\mathrm{P}_{\text {el_ST }}(\mathrm{kW})$ & 2499.24 & 2078.91 & 1879.93 \\
\hline \multirow{3}{*}{ PT } & $\dot{\mathrm{m}}_{\mathrm{e}}(\mathrm{kg} / \mathrm{s})$ & 11.87 & 9.27 & 0 \\
\hline & $\mathrm{p}_{\text {in }}(\mathrm{bar})$ & 3.33 & 2.57 & 0 \\
\hline & $\mathrm{P}_{\mathrm{el} \_\mathrm{PT}}(\mathrm{kW})$ & 1922.35 & 1139.58 & 0 \\
\hline \multirow{3}{*}{$\mathrm{ME}$} & $\mathrm{P}_{\mathrm{ME}}(\mathrm{kW})$ & 43,920 & 31,972 & 21,960 \\
\hline & $\mathrm{P}_{\mathrm{SM}}(\mathrm{kW})$ & 0 & 967.57 & 0 \\
\hline & HFO (t/h) & 7.32 & 5.31 & 3.72 \\
\hline \multirow{2}{*}{ DGs } & $\mathrm{P}_{\mathrm{DGs}}(\mathrm{kW})$ & 578.41 & 0.0 & $2,620.07$ \\
\hline & MDO (t/h) & 0.14 & 0 & 0.55 \\
\hline
\end{tabular}

6 For the above simulated sea passage condition the Sankey diagram shown in Figure 11 displays the energy conversions throughout the on-board energy system, including the recovered energy by the ST2PT WHRS. Starting with the fuel energy on the left side, only roughly $50 \%$ is finally converted into propulsion; the remaining energy is given back as heat to the surrounding environment, either via the cooling system (20.32\%) or exhaust gas system (29.07\%). Within the

10 ST2PT WHRS, one part of the exhaust gas heat energy is directly recovered by the power turbine into mechanical 11 energy (roughly $4.76 \%$ with respect to the main engine load, i.e. $2.09 \mathrm{MW} / 43.92 \mathrm{MW}$ ) and a further part by the dual12 pressure level steam turbine (i.e. $2.71 \mathrm{MW} / 43.92 \mathrm{MW}=6.17 \%$ ) providing a total WHRS electrical power production 13 of $10.06 \%$ with respect to the main engine load (and 5.10\% regarding the original fuel energy). This overall results in a 14 main engine efficiency of about $55.73 \%$. 


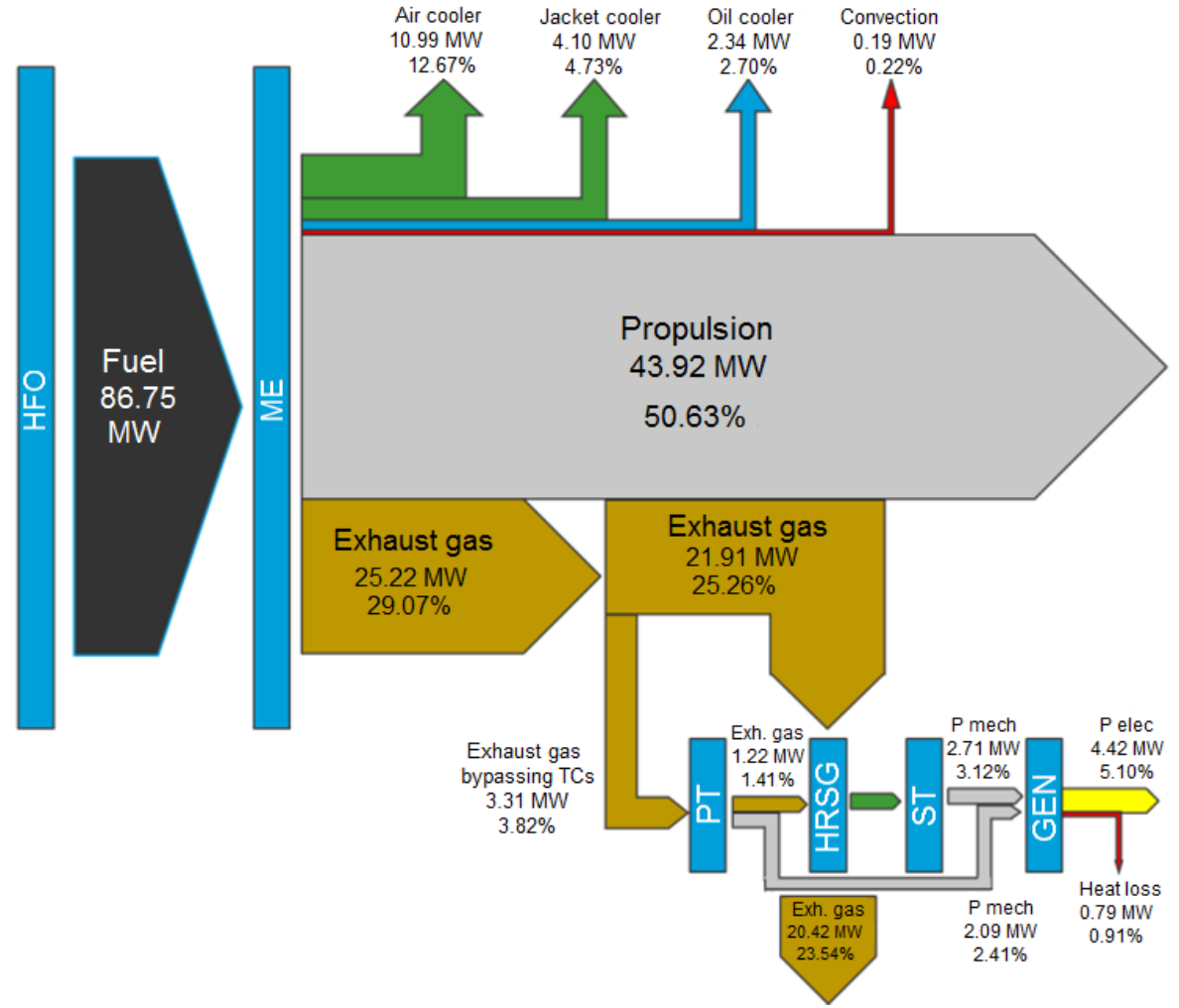

Figure 11: Sankey diagram for ST2PT sea passage condition

2 Table 5 shows the overall fuel consumption of HFO for the main engine and MDO for auxiliary engines, together with

3 related savings. Table 5 shows annual savings of nearly 2 million USD, assuming the above stated fuel costs. The

4 investment cost for a properly dimensioned ST2PT WHRS matching the example container vessel is estimated at around

510 million USD, according to a rough estimation based on MAN Diesel \& Turbo (2011). This investment includes the

6 costs for the steam turbine, power turbine, shaft motor, dual pressure HRSG, power management system, exhaust gas

7 boiler and installation costs. Thus, in this case the payback period is roughly 5 years.

8 Table 5: Fuel consumption, costs and savings

\begin{tabular}{lrrrr}
\hline & $\begin{array}{c}\text { HFO } \\
\text { (t/year) }\end{array}$ & \multicolumn{1}{c}{$\begin{array}{c}\text { HFO } \\
\text { (USD/year) }\end{array}$} & \multicolumn{1}{c}{$\begin{array}{c}\text { MDO } \\
\text { (t/year })\end{array}$} & \multicolumn{1}{c}{$\begin{array}{c}\text { MDO } \\
\text { (USD/year) }\end{array}$} \\
\hline No WHR & 39,596 & $11,878,812$ & 6,989 & $3,145,230$ \\
\hline ST2PT & 39,733 & $11,919,795$ & 2,542 & $1,144,044$ \\
\hline Savings & -137 & $-40,983$ & 4,447 & $2,001,186$ \\
\hline
\end{tabular}

9

\section{$10 \quad$ 5.1.2 Large container with ST1}

11 The second example considers the WHRS as single pressure level steam turbine, ST1, as shown in Figure 12. This WHR

12 solution is typically able to recover a medium amount of energy. 


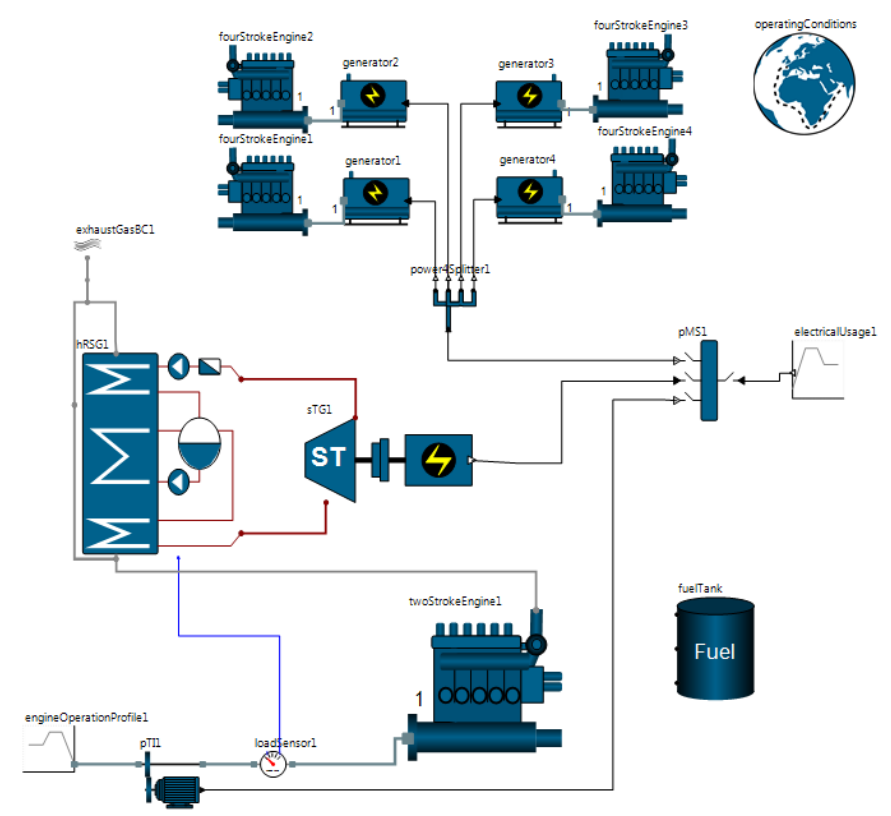

Figure 12: Case study simulation model with ST1

2 For this example, the same vessel particulars, mission profile and operating conditions apply - and only the WHRS

3 design has changed. Table 6 shows the results of the simulation in case of the ST1 WHRS, considering a 1.7 MW steam

4 turbine. Table 6 shows that during sea passage, ballast and slow steaming conditions, the electrical demand is partly

5 covered by the ST1 WHRS, leading to reduced MDO consumption. At no time the WHRS runs at a point where surplus

6 electrical power for the shaft motor is produced. So, no main engine fuel is saved. Manoeuvring and port stay are again

7 not displayed, since no difference to the baseline case exist.

8 Table 6: Simulation results large container - ST1

\begin{tabular}{llrrr}
\hline & & Sea passage & \multicolumn{1}{c}{ Ballast } & \multicolumn{1}{c}{ Slow steaming } \\
\hline \multirow{3}{*}{ ST1-G } & $\dot{\mathrm{m}}_{\mathrm{s}}(\mathrm{kg} / \mathrm{s})$ & 3.31 & 2.80 & 2.47 \\
\cline { 2 - 5 } & $\mathrm{T}_{\mathrm{s}}^{\text {in }}\left({ }^{\circ} \mathrm{C}\right)$ & 241.2 & 245.1 & 264.6 \\
\cline { 2 - 5 } & $\mathrm{P}_{\text {el_ST }}(\mathrm{kW})$ & 1,543 & 1,310 & 1,182 \\
\hline \multirow{2}{*}{ DGs } & $\mathrm{P}_{\text {DGs }}(\mathrm{kW})$ & 3,457 & 890 & 3,318 \\
\cline { 2 - 5 } & MDO $(\mathrm{t} / \mathrm{h})$ & 0.75 & 0.20 & 0.73
\end{tabular}

10 The annual savings of MDO sum up to 1,841 tons, which corresponds to 0.83 million USD, assuming the above stated 11 price for diesel oil. Assuming total investment costs of 6 million USD for the ST1 waste heat recovery system, the

12 payback period in this case is approximately 7 years. 


\subsubsection{Large container with PT}

2 The third example investigates a power turbine as WHRS solution for the above operational profile. Depending on the size of the power turbine, a small to medium amount of energy can be recovered. The results for a $2 \mathrm{MW}$ power turbine are given in Table 7 which shows that, during slow steaming, the exhaust gas flow of the main engine bypasses the PT. In case of seagoing and ballast conditions the electrical demand is partly covered by the WHRS, leading to reduced MDO consumption. Similar to the ST1 case, for this set-up at no time surplus electrical power for the shaft motor is produced.

8 The annual savings of MDO sum up to 1,742 tons, which corresponds to 0.78 million USD, assuming the above stated 9 price for diesel oil. Assuming total investment costs of 3 million USD for the PT waste heat recovery system, the 10 payback period is approximately 4 years.

11 Table 7: Simulation results large container - PT

\begin{tabular}{llrrr}
\hline & & Sea passage & \multicolumn{1}{c}{ Ballast } & \multicolumn{1}{c}{ Slow steaming } \\
\hline \multirow{3}{*}{ PT } & $\dot{m}_{e}(\mathrm{~kg} / \mathrm{s})$ & 11.87 & 9.50 & 0 \\
\cline { 2 - 5 } & $P_{\text {in }}(\mathrm{bar})$ & 3.33 & 2.64 & - \\
\cline { 2 - 5 } & $P_{\text {el_PT }}(\mathrm{kW})$ & 1922.4 & 1201.1 & 0 \\
\hline \multirow{2}{*}{ DGs } & $P_{D G S}(\mathrm{~kW})$ & 3077.6 & 999.9 & 4500 \\
\cline { 2 - 5 } & MDO $(\mathrm{t} / \mathrm{h})$ & 0.64 & 0.22 & 0.94 \\
\hline
\end{tabular}

\section{$12 \quad 5.2$ Dependability analysis}

13 The HiP-HOPS tool has automatically carried out calculations of system failure probability. For the WHRS

14 arrangements defined in subsection 3.1, the analysis was done within a few seconds. In Table 8, the resulting WHRS

15 failure probabilities of the respective output deviation modes at the PTI output after one month of operation, i.e. after $t=$ 16720 operating hours, are given. The failure probabilities are listed in descending order. Thereby, not only the mean 17 values for the failure rates from Table 1, but the lower and upper values from (OREDA, 2009) have been used as well, 18 respectively reflected in resulting lower, mean and upper system failure probabilities. The events with higher mean 19 values are listed first, lower and upper values do not necessarily follow this ranking.

Table 8: WHRS failure probability for deviation classes at PTI output after one month operation

\begin{tabular}{lrrr}
\hline \multirow{2}{*}{ Fault Tree Top Event } & \multicolumn{3}{c}{ System failure probability } \\
\cline { 2 - 4 } & \multicolumn{1}{c}{ Lower value } & \multicolumn{1}{c}{ Mean value } & \multicolumn{1}{c}{ Upper value } \\
\hline Red-ST2PT & $4.17 \mathrm{E}-02$ & $3.45 \mathrm{E}-01$ & $7.38 \mathrm{E}-01$ \\
\hline Low-ST2PT & $1.47 \mathrm{E}-02$ & $3.34 \mathrm{E}-01$ & $8.64 \mathrm{E}-01$ \\
\hline Low-ST1 & $2.12 \mathrm{E}-02$ & $2.56 \mathrm{E}-01$ & $6.32 \mathrm{E}-01$ \\
\hline Red-ST2PT_R & $4.03 \mathrm{E}-02$ & $2.37 \mathrm{E}-01$ & $5.99 \mathrm{E}-01$ \\
\hline Om-ST1 & $1.04 \mathrm{E}-02$ & $2.29 \mathrm{E}-01$ & $6.57 \mathrm{E}-01$ \\
\hline
\end{tabular}




\begin{tabular}{lccc}
\hline \multirow{2}{*}{ Fault Tree Top Event } & \multicolumn{2}{c}{ System failure probability } \\
\cline { 2 - 4 } & Lower value & Mean value & Upper value \\
\hline Low-ST2PT_R & $1.46 \mathrm{E}-02$ & $2.23 \mathrm{E}-01$ & $7.13 \mathrm{E}-01$ \\
\hline Low-ST1_R & $2.04 \mathrm{E}-02$ & $1.97 \mathrm{E}-01$ & $5.45 \mathrm{E}-01$ \\
\hline Om-ST1_R & $1.03 \mathrm{E}-02$ & $1.62 \mathrm{E}-01$ & $5.33 \mathrm{E}-01$ \\
\hline Low-PT & $2.03 \mathrm{E}-02$ & $1.54 \mathrm{E}-01$ & $4.10 \mathrm{E}-01$ \\
\hline Om-PT & $9.36 \mathrm{E}-03$ & $1.48 \mathrm{E}-01$ & $4.09 \mathrm{E}-01$ \\
\hline Om-ST2PT & $3.43 \mathrm{E}-03$ & $1.15 \mathrm{E}-01$ & $4.27 \mathrm{E}-01$ \\
\hline Om-ST2PT_R & $3.43 \mathrm{E}-03$ & $1.09 \mathrm{E}-01$ & $3.62 \mathrm{E}-01$ \\
\hline LL-ST2PT & $1.69 \mathrm{E}-06$ & $1.50 \mathrm{E}-02$ & $2.34 \mathrm{E}-01$ \\
\hline LL-ST1 & $2.43 \mathrm{E}-06$ & $1.01 \mathrm{E}-02$ & $1.12 \mathrm{E}-01$ \\
\hline LL-ST2PT_R & $1.68 \mathrm{E}-06$ & $8.56 \mathrm{E}-03$ & $1.49 \mathrm{E}-01$ \\
\hline LL-ST1_R & $2.34 \mathrm{E}-06$ & $7.15 \mathrm{E}-03$ & $8.62 \mathrm{E}-02$ \\
\hline LL-PT & $2.33 \mathrm{E}-06$ & $5.02 \mathrm{E}-03$ & $5.08 \mathrm{E}-02$ \\
\hline Exc-ST2PT_R & $2.16 \mathrm{E}-05$ & $1.08 \mathrm{E}-03$ & $3.34 \mathrm{E}-03$ \\
\hline Exc-ST2PT & $2.16 \mathrm{E}-05$ & $1.08 \mathrm{E}-03$ & $3.34 \mathrm{E}-03$ \\
\hline Exc-ST1_R & $7.20 \mathrm{E}-06$ & $3.60 \mathrm{E}-04$ & $1.12 \mathrm{E}-03$ \\
\hline Exc-ST1 & $7.20 \mathrm{E}-06$ & $3.60 \mathrm{E}-04$ & $1.12 \mathrm{E}-03$ \\
\hline Exc-PT & $7.20 \mathrm{E}-06$ & $3.60 \mathrm{E}-04$ & $1.12 \mathrm{E}-03$ \\
\hline
\end{tabular}

The probability of the event "reduced power output of ST2PT" (Red-ST2PT) using mean failure rate values is $34.5 \%$ as shown in the middle of the first row of Table 8. This is the event with the largest mean failure probability (applying mean component failure rate values). However, the probability that the same WHRS arrangement fails to deliver any power at all (Om-ST2PT, row 11 of Table 8$)$ is only $11.5 \%$, which is lower than the omission probability for the simpler arrangements with only ST1 (Om-ST1: $22.9 \%$ in row 5) or PT (Om-PT: 14.8\%, row 10). In general, the event of an omission of output is less probable than a reduced or low output failure for the same system.

8 The positive influence of having redundant circulation pumps for the steam circuit can be seen, e.g. by comparing the

9 failure probabilities of ST2PT and ST2PT_R. The probability of the deviation class 'Red' is reduced from 34.5\% to

$1023.7 \%$ for Red-ST2PT_R, which means it is significantly more reliable.

11 The failure probabilities for the output deviation class "excess of power output" (Exc) are listed in the last rows of Table

12 8. In the system model, an excess of power is caused by a failure of the control valves, and the resulting probability is

13 proportional to the number of these valves. The arrangement ST2PT has three inlet control valves, one for the power

14 turbine exhaust gas and two for the dual pressure steam turbine, whereas ST1 and PT have each only one. 
Table 9: WHRS Minimal Cut Sets for unreliability for deviation classes at PTI output

\begin{tabular}{|c|c|c|c|c|c|c|c|}
\hline \multirow{3}{*}{$\begin{array}{l}\text { Fault Tree } \\
\text { Top Event }\end{array}$} & \multicolumn{7}{|c|}{ Minimal Cut Sets } \\
\hline & \multirow{2}{*}{ Total } & \multicolumn{6}{|c|}{ Order } \\
\hline & & 1 & 2 & 3 & 4 & 5 & 6 \\
\hline Red-ST2PT & 13 & 13 & 0 & 0 & 0 & 0 & 0 \\
\hline Low-ST2PT & 87 & 15 & 72 & 0 & 0 & 0 & 0 \\
\hline Low-ST1 & 8 & 8 & 0 & 0 & 0 & 0 & 0 \\
\hline Red-ST2PT_R & 13 & 11 & 2 & 0 & 0 & 0 & 0 \\
\hline Om-ST1 & 87 & 13 & 53 & 20 & 1 & 0 & 0 \\
\hline Low-ST2PT_R & 26 & 8 & 18 & 0 & 0 & 0 & 0 \\
\hline Low-ST1_R & 8 & 7 & 1 & 0 & 0 & 0 & 0 \\
\hline Om-ST1_R & 26 & 7 & 14 & 5 & 0 & 0 & 0 \\
\hline Low-PT & 5 & 5 & 0 & 0 & 0 & 0 & 0 \\
\hline Om-PT & 11 & 5 & 6 & 0 & 0 & 0 & 0 \\
\hline Om-ST2PT & 326 & 2 & 30 & 177 & 117 & 0 & 0 \\
\hline Om-ST2PT_R & 326 & 2 & 24 & 126 & 126 & 45 & 3 \\
\hline LL-ST2PT & 86 & 0 & 14 & 72 & 0 & 0 & 0 \\
\hline LL-ST1 & 7 & 0 & 7 & 0 & 0 & 0 & 0 \\
\hline LL-ST2PT_R & 86 & 0 & 12 & 53 & 20 & 1 & 0 \\
\hline LL-ST1_R & 7 & 0 & 6 & 1 & 0 & 0 & 0 \\
\hline LL-PT & 4 & 0 & 4 & 0 & 0 & 0 & 0 \\
\hline Exc-ST2PT_R & 3 & 3 & 0 & 0 & 0 & 0 & 0 \\
\hline Exc-ST2PT & 3 & 3 & 0 & 0 & 0 & 0 & 0 \\
\hline Exc-ST1_R & 1 & 1 & 0 & 0 & 0 & 0 & 0 \\
\hline Exc-ST1 & 1 & 1 & 0 & 0 & 0 & 0 & 0 \\
\hline Exc-PT & 1 & 1 & 0 & 0 & 0 & 0 & 0 \\
\hline
\end{tabular}

3 Table 9 lists the "Minimal Cut Sets" (MCS) of the respective fault tree, i.e. minimal sets of failure modes causing a

4 system failure. These sets are minimal in the sense that if any of the failure modes in the set does not occur, no system

5 failure is expected from the remaining failure modes in the MCS. Thereby the fault tree events are listed in the same

6 order as in Table 8. The MCSs are classified according to their order, i.e. a MCS of order one consists of single failure

7 mode (i.e. a single point of failure), a MCS of order two is a combination of two failure modes causing system failure

8 and so on. They can be seen as the basic building blocks of a fault tree. The number of MCS listed in Table 9 reveals the

9 complexity of the system. The systems with the largest number of components, namely ST2PT and ST2PT_R have fault

10 trees with the largest number of MCS, i.e. Om-ST2PT and Om-ST2PT_R with 326 MCS. However, as the failure

11 probability shows, the redundant pumps arrangement of ST2PT_R translates in a lower failure probability. Although the

12 number of MCS is the same, there is a lower amount of second and third order MCS in the redundant pumps 
arrangement ST2PT_R compared to the slightly simpler ST2PT, and at the same time MCS of order five (45) and six (3) appear.

3 The number of MCS of first order can act as a qualitative indicator of the failure probability. The largest fault trees with 4326 MCS only have two MCS of first order; and a lower probability of system failure compared to other deviation

5 classes of these WHRS arrangements.

6 To assess the uncertainty of the results, Figure 13 shows a range of the system failure probabilities for each deviation class. For the determination of the failure probabilities calculated in Table 8 the component failure rates stated in Table 1 have been used. These values can be found as mean failure probabilities in Figure 13. For the determination of lower and upper estimates for the failure probability of a deviation class, corresponding lower and upper estimates of the single

10 component failure rates are employed. In the OREDA handbook (OREDA, 2009) failure rate values for the 5\% and 95\% 11 percentiles of the underlying Chi-squared distribution are given as well, yielding the commonly used $90 \%$ confidence 12 interval. These 5\% and 95\% percentile values of the component failure rates are used for computing the lower and upper 13 failure probabilities for all deviation classes. The results are displayed in Figure 13. Since the failure probabilities are 14 dominated by MCS of first order it can be assumed that the given range also corresponds to a $90 \%$ confidence interval.

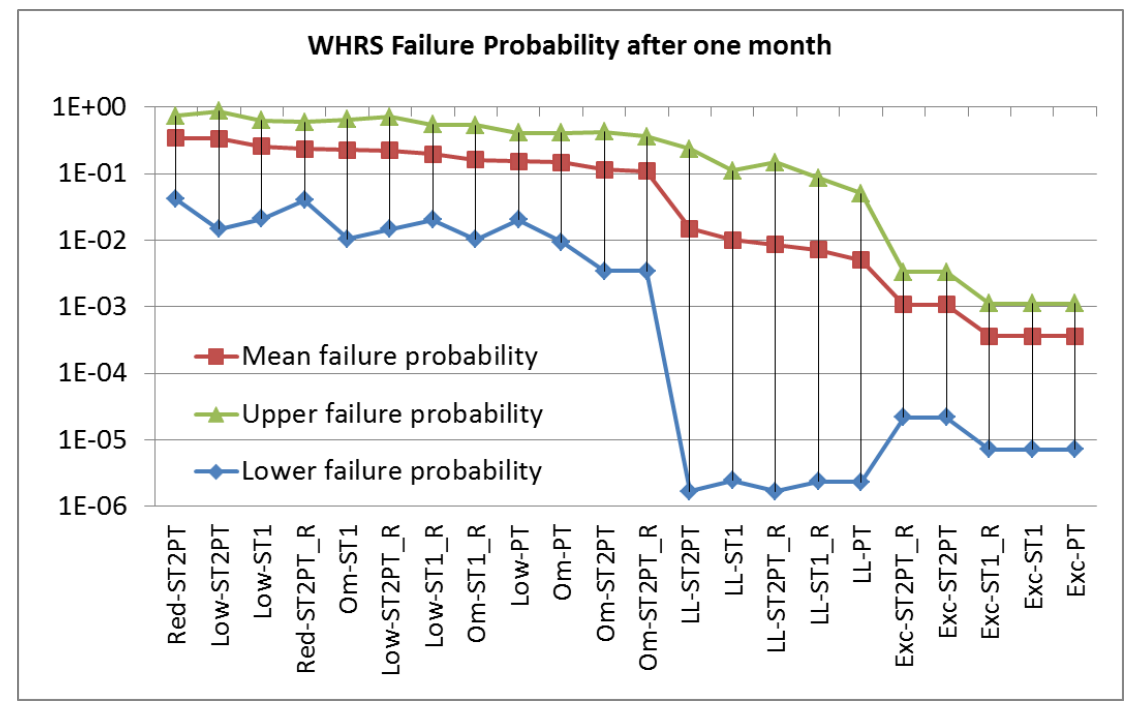

Figure 13: Range of WHRS failure probabilities at PTI output, using upper/mean/lower failure rates

15

16 The system unavailability $Q(t)$ is the probability that the system is down at time $t$ and unable to operate if called on. To 17 determine the system unavailability, not only failure rates, but also repair and replacement times are required, i.e. the 18 Mean Time To Repair. The MTTR is assumed to consider the complete downtime including logistic, preparation and repair times for all different failure modes, see values given in Table 1 from (OREDA, 2009). 
1 The system unavailability of the different WHRS arrangements for the deviation classes at generator output is given in

2 Table 10. The stated values can be considered as steady-state values. The lower, mean and upper unavailability values

3 are (analogously to the failure probability) based on the lower, mean and upper failure rates of the single components.

4 Table 10: Range of WHRS unavailability for the deviation classes at generator output

\begin{tabular}{lccc}
\hline \multirow{2}{*}{ Fault Tree Top Event } & \multicolumn{2}{c}{ System unavailability } \\
\cline { 2 - 4 } & Lower value & Mean value & Upper value \\
\hline Low-ST2PT_e & $1.86 \mathrm{E}-03$ & $1.94 \mathrm{E}-02$ & $5.96 \mathrm{E}-02$ \\
\hline Low-ST2PT_R_e & $1.86 \mathrm{E}-03$ & $1.63 \mathrm{E}-02$ & $4.70 \mathrm{E}-02$ \\
\hline Om-ST1_e & $1.00 \mathrm{E}-03$ & $1.13 \mathrm{E}-02$ & $3.43 \mathrm{E}-02$ \\
\hline Om-ST1_R_e & $1.00 \mathrm{E}-03$ & $9.77 \mathrm{E}-03$ & $2.78 \mathrm{E}-02$ \\
\hline Om-PT_e & $9.11 \mathrm{E}-04$ & $8.62 \mathrm{E}-03$ & $2.42 \mathrm{E}-02$ \\
\hline Red-ST2PT_e & $6.99 \mathrm{E}-04$ & $6.88 \mathrm{E}-03$ & $2.32 \mathrm{E}-02$ \\
\hline Red-ST2PT_R_e & $6.82 \mathrm{E}-04$ & $5.07 \mathrm{E}-03$ & $1.73 \mathrm{E}-02$ \\
\hline Low-ST1_e & $3.53 \mathrm{E}-04$ & $4.85 \mathrm{E}-03$ & $1.71 \mathrm{E}-02$ \\
\hline Low-ST1_R_e & $3.44 \mathrm{E}-04$ & $3.94 \mathrm{E}-03$ & $1.41 \mathrm{E}-02$ \\
\hline Low-PT_e & $3.43 \mathrm{E}-04$ & $2.85 \mathrm{E}-03$ & $9.12 \mathrm{E}-03$ \\
\hline Om-ST2PT_e & $7.14 \mathrm{E}-05$ & $2.36 \mathrm{E}-03$ & $7.56 \mathrm{E}-03$ \\
\hline Om-ST2PT_R_e & $7.14 \mathrm{E}-05$ & $2.34 \mathrm{E}-03$ & $7.33 \mathrm{E}-03$ \\
\hline LL-ST2PT_e & $2.68 \mathrm{E}-09$ & $9.71 \mathrm{E}-06$ & $1.29 \mathrm{E}-04$ \\
\hline LL-ST2PT_R_e & $2.62 \mathrm{E}-09$ & $7.15 \mathrm{E}-06$ & $9.59 \mathrm{E}-05$ \\
\hline Exc-ST2PT_R_e & $6.00 \mathrm{E}-08$ & $3.00 \mathrm{E}-06$ & $9.30 \mathrm{E}-06$ \\
\hline Exc-ST2PT_e & $6.00 \mathrm{E}-08$ & $3.00 \mathrm{E}-06$ & $9.30 \mathrm{E}-06$ \\
\hline Exc-ST1_R_e & $2.00 \mathrm{E}-08$ & $1.00 \mathrm{E}-06$ & $3.10 \mathrm{E}-06$ \\
\hline Exc-ST1_e & $2.00 \mathrm{E}-08$ & $1.00 \mathrm{E}-06$ & $3.10 \mathrm{E}-06$ \\
\hline Exc-PT_e & $2.00 \mathrm{E}-08$ & $1.00 \mathrm{E}-06$ & $3.10 \mathrm{E}-06$ \\
\hline & & & \\
\hline & & & \\
\hline
\end{tabular}

6 For easier inspection, the values from Table 10 are visualized in Figure 14. In Figure 14, similar to the failure probability

7 case, the corresponding $90 \%$ confidence intervals considering the failure rate values (no variation in the MTTR values

8 considered) for the unavailability of the considered deviation classes are displayed. 


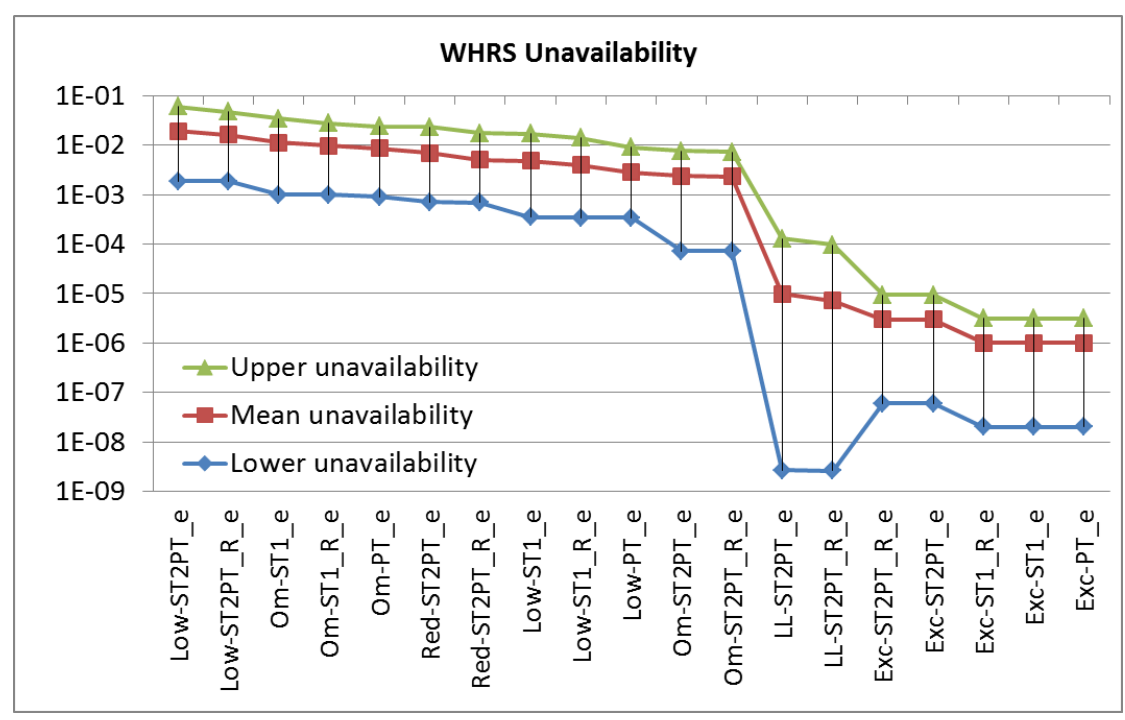

Figure 14: WHRS unavailability calculated with upper, mean and lower failure rates

2 The ranking of the WHRS unavailability in Table 10 from high to low (for the mean values) is slightly different from the 3 ranking of the failure probability in Table 8. The reason for this is mainly the effect of repair times on the unavailability.

4 An unreliable component, i.e. one with a high failure probability that is repaired and put back in service in a short time 5 can have a higher availability than a reliable component, i.e. with low failure probability that requires a relatively long

6 time for repair and being put back to service. As an example, the failure rate of the HRSG pump for the failure mode

7 Degraded is considered. With $114.16 \mathrm{E}-6$ per hour this is the largest value among all considered components, but the

8 respective MTTR of 8 hours is one of the shortest and, thus, the (steady state) unavailability of 9.12E-04 is not the

9 highest among the components. The components with the largest unavailability are the steam and power turbines in the

10 failure mode Critical, i.e. with a value of $6.10 \mathrm{E}-03$ this is roughly seven times larger than the above mentioned HRSG

11 failure mode pumpDegraded.

\section{$12 \quad 5.3$ Economic Analysis and Results}

13 To connect energy computational results with the results from the dependability analysis both are translated to costs.

14 This is done via estimates on fuel savings, repair costs and downtime costs, i.e. when the WHRS is not able to generate

15 any power and the required electrical energy has to be produced by a standard auxiliary diesel generator which relates to

16 fuel costs.

17 All input data used for the economic analysis has been determined in the previous subsections. The used fuel prices, i.e.

$18 \mathrm{HFO}$ at $300 \mathrm{USD} /$ ton and MDO at $450 \mathrm{USD} /$ ton, are subject to changes. Therefore, the stated economic results should

19 only be used in relative terms, in absolute terms it is only valid if the fuel oil prices are around the assumed values. 
1 The operational profiles for the main and auxiliary engines are modelled as discrete distribution function. Output power

2 of the PT and ST is delivered if the ME load is above 50\% MCR and 35\% MCR respectively. Typically, the power

3 recovered by the WHRS saves a certain amount of MDO, used by the diesel generators. Moreover, in case the generated

4 power by the WHRS exceeds the electrical demand, this excess power is used via a shaft motor for propulsion, and thus

5 thereby saving a certain amount of HFO.

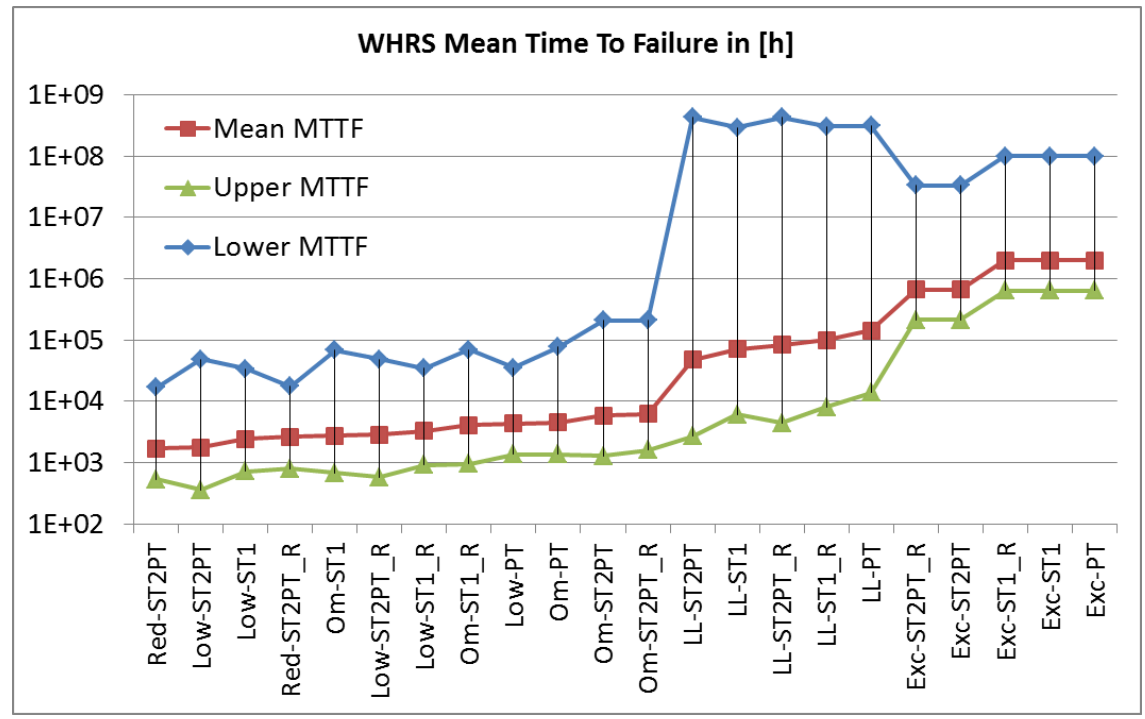

Figure 15: WHRS mean time to failure; calculated with upper, mean and lower failure rates

7 For the unreliability, the mean time to failure (MTTF) is regarded for all deviation classes. In Figure 15, the respective

8 values are displayed for the MTTF mean, as well as upper and lower values. These values, together with the

9 corresponding MTTR, can be used to determine how often each output deviation occurs within one year (one year is

10 considered as 330 operating days, yielding 7920 hours). The results are listed in Table 11.

11 Table 11: Number of annual failures for the deviation classes at PTI output

\begin{tabular}{llcl}
\hline \multirow{2}{*}{ Fault Tree Top Event } & \multicolumn{3}{c}{ Number of failures per year } \\
\cline { 2 - 4 } & Lower value & Mean value & Upper value \\
\hline Red-ST2PT & $4.7 \mathrm{E}-01$ & 4.7 & 14.7 \\
\hline Low-ST2PT & $1.6 \mathrm{E}-01$ & 4.5 & 22.0 \\
\hline Low-ST1 & $2.4 \mathrm{E}-01$ & 3.3 & 11.0 \\
\hline Red-ST2PT_R & $4.5 \mathrm{E}-01$ & 3.0 & 10.0 \\
\hline Om-ST1 & $1.1 \mathrm{E}-01$ & 2.9 & 11.8 \\
\hline Low-ST2PT_R & $1.6 \mathrm{E}-01$ & 2.8 & 13.7 \\
\hline Low-ST1_R & $2.3 \mathrm{E}-01$ & 2.4 & 8.7 \\
\hline Om-ST1_R & $1.1 \mathrm{E}-01$ & 2.0 & 5.8 \\
\hline Low-PT & $2.3 \mathrm{E}-01$ & 1.8 & \\
\hline
\end{tabular}




\begin{tabular}{llll}
\hline \multirow{2}{*}{ Fault Tree Top Event } & \multicolumn{3}{c}{ Number of failures per year } \\
\cline { 2 - 4 } Om-PT & Lower value & Mean value & Upper value \\
\hline Om-ST2PT & $3.0 \mathrm{E}-01$ & 1.8 & 5.8 \\
\hline Om-ST2PT_R & $3.8 \mathrm{E}-02$ & 1.3 & 6.1 \\
\hline LL-ST2PT & $1.9 \mathrm{E}-05$ & 1.3 & 4.9 \\
\hline LL-ST1 & $2.7 \mathrm{E}-05$ & $1.7 \mathrm{E}-01$ & 2.9 \\
\hline LL-ST2PT_R & $1.8 \mathrm{E}-05$ & $9.5 \mathrm{E}-02$ & 1.3 \\
\hline LL-ST1_R & $2.6 \mathrm{E}-05$ & $7.9 \mathrm{E}-02$ & 1.0 \\
\hline LL-PT & $2.6 \mathrm{E}-05$ & $5.5 \mathrm{E}-02$ & $5.7 \mathrm{E}-01$ \\
\hline Exc-ST2PT_R & $2.4 \mathrm{E}-04$ & $1.2 \mathrm{E}-02$ & $3.7 \mathrm{E}-02$ \\
\hline Exc-ST2PT & $2.4 \mathrm{E}-04$ & $1.2 \mathrm{E}-02$ & $3.7 \mathrm{E}-02$ \\
\hline Exc-ST1_R & $7.9 \mathrm{E}-05$ & $4.0 \mathrm{E}-03$ & $1.2 \mathrm{E}-02$ \\
\hline Exc-ST1 & $7.9 \mathrm{E}-05$ & $4.0 \mathrm{E}-03$ & $1.2 \mathrm{E}-02$ \\
\hline Exc-PT & $7.9 \mathrm{E}-05$ & $4.0 \mathrm{E}-03$ & $1.2 \mathrm{E}-02$ \\
\hline
\end{tabular}

2 These values are used as supporting points for a continuous distribution function for the subsequent analysis. For this case study the distribution function has been chosen to be of Weibull type; please note that other common distribution functions (Lognormal, Gauss) yield very similar results. A Weibull distribution is defined for positive values only, which is a reasonable choice for the MTTF parameter. Note that by choosing a Gaussian distribution the property of non-negativity would have been lost. The Weibull probability density function is given by $p(x)=k / b \cdot(x / b)^{k-1}$. $e^{-(x / b)^{k}}$ with the corresponding cumulative distribution function $P_{c u m}(x)=\int_{0}^{x} p(y) d y=1-e^{-(x / b)^{k}}$ where $k$ is the

8 Weibull shape parameter and $b$ the scale parameter. The two parameters are related via the median value $x_{m}=b$.

$9 \quad[\ln (2)]^{1 / k}$. These parameters are adjusted to obtain the best fitting Weibull distributions for each set of supporting 10 points.

11 The repair costs are roughly estimated as ratios with respect to the initial investment costs. Real repair cost data was not 12 available to the authors, thus, estimates based on discussion with ship operation experts was used as approximations 13 instead. The output deviation class excess is considered as the worst case, since it is very likely that after a short time of 14 delivering more than $100 \%$ output power a serious failure will occur. For Exc a ratio of $1 \%$ with respect to investment 15 costs is considered, i.e. this is 100,000 USD for Exc-ST2PT. For Om the ratio is assumed 0.25\%, for LowLow 0.15\%, 16 for Low $0.1 \%$ and for Red $0.05 \%$, respectively. This yields costs of 5,000 USD for Red-ST2PT, i.e. to fix a minor failure 17 coming from the Degraded failure mode of a system component. 
1 The resulting probability density function of the annual repair costs for a WHRS arrangement is the sum of the fitted

2 Weibull distribution functions of the corresponding annual failures of the deviation classes multiplied by the respective

3 repair cost: $p_{W H R S}^{\text {repair costs }}=\sum_{i} p_{W H R S \text { dev. class } i}^{\text {annual failure }} \cdot x_{W H R S \text { dev. } \text { class } i}^{\text {repair costs }}$.

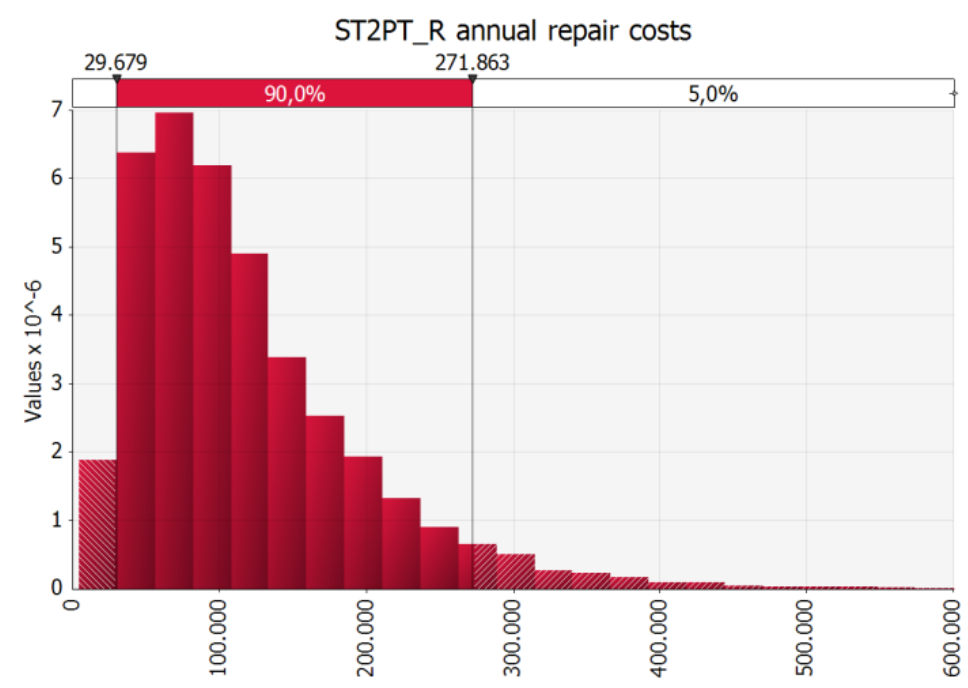

Figure 16: Probability distribution of repair costs in USD per year for ST2PT_R WHRS

5 After inserting all data in the analysis tool and choosing a sufficiently large number of experiments for the Monte Carlo

6 simulation, the simulation itself is carried out in a few seconds. The result for ST2PT_R is shown in Figure 16. The

7 mean value of this distribution is $106,651 \mathrm{USD} /$ year.

8 For the unavailability, the lower, mean and upper values of Table 10 are considered, by again employing a best fit

9 Weibull distribution matching the determined percentile values for each deviation class at generator output, i.e.

$10 \quad q_{W H R S \text { dev. class } i}^{\text {unavailabitity }}$

11 The reduced power output of all deviation classes is modelled by a corresponding uniform distribution according to the

12 intervals given in Figure 9. The excess state is hereby considered as a zero-power output, since it is assumed that after a

13 short time the system collapses into the omission state. It is further assumed that at half of the MTTR the system is still

14 delivering the reduced power output, and at the other half the system is being repaired and therefore switched off. These

15 two effects are considered by $r_{W H R S \text { dev. class } i}^{\text {power reduction }}$, the uniform power reduction distribution function for each deviation

16 class. For obtaining the resulting costs due to unavailability of the generator output the sum over the deviation classes of

17 the products of the latter two have to be multiplied by the annual savings $c_{W H R S}^{\text {savings }}$ of the respective WHRS: 
For the unavailability costs with respect to the shaft motor output, an additional case has to be considered. The shaft motor is only used in case of the ST2PT and ST2PT_R WHRSs in the ballast condition, and only affects the consumption of HFO. Hence, the additional case to consider is a running WHRS producing additional power, i.e. being available in this condition, and a deteriorated PTI. The following cases are distinguished in Table 12. They are combined with the above defined output deviation classes of the generator, finally yielding slight changes of the values for $q_{W H R S \text { dev. class } i}^{\text {unavailability }}$ and $r_{W H R S \text { dev. class } i}^{\text {power redion }}$ in the above formula.

Table 12: Shaft motor unavailability

\begin{tabular}{lccc}
\hline \multirow{2}{*}{ Failure Mode } & \multicolumn{3}{c}{ Shaft motor unavailability } \\
\cline { 2 - 4 } & Lower value & Mean value & Upper value \\
\hline PTI degraded & $3.84 \mathrm{E}-06$ & $1.41 \mathrm{E}-03$ & $5.51 \mathrm{E}-03$ \\
\hline PTI critical & $7.05 \mathrm{E}-05$ & $2.28 \mathrm{E}-03$ & $6.89 \mathrm{E}-03$ \\
\hline
\end{tabular}

9 In Figure 17, the probability density function for the annual unavailability costs after the PTI output is shown for the

10 ST2PT_R arrangement. This distribution contains the above defined modified sum of the products of the unavailability

11 probability distribution functions of all respective deviation classes, i.e. Red-ST2PT_R, Low-ST2PT_R, LowLow-

12 ST2PT_R, Om-ST2PT_R and Exc-ST2PT_R and their respective power reduction functions. The mean value of the

13 distribution is 42,562 USD/year. The large bar at zero costs is due to the considered discrete input probability function

14 for the main engine operational profile, i.e. there is a certain probability that the ME load is so small that the WHRS is

15 not running, and thus the potential unavailability has no effect.

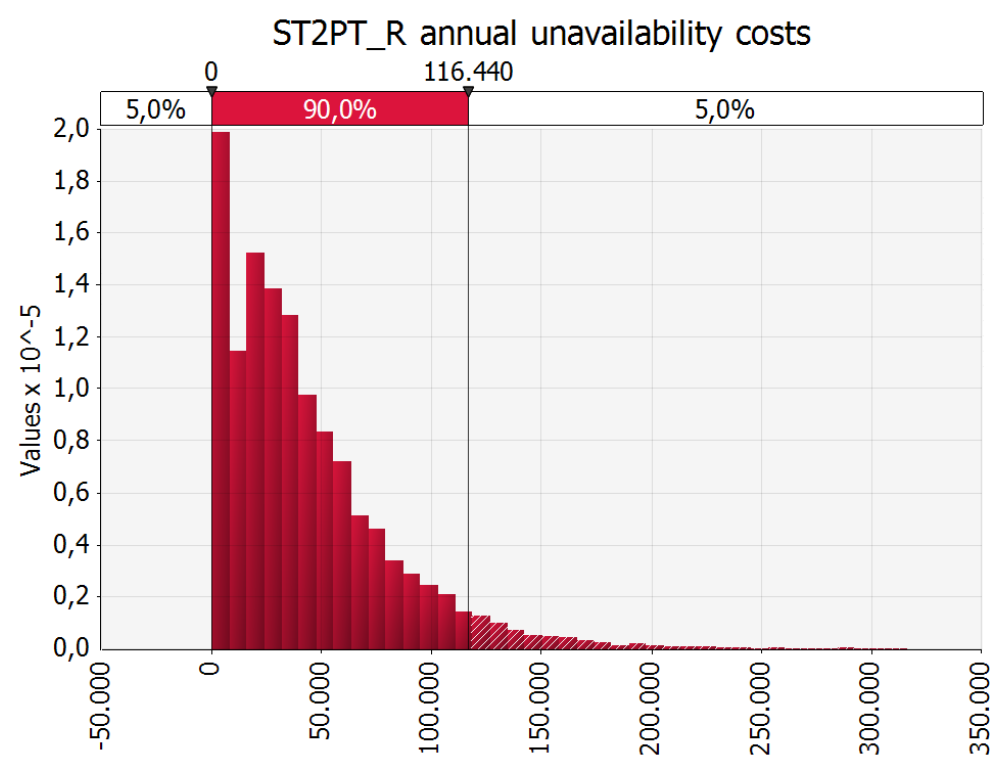

Figure 17: Probability distribution of unavailability costs in USD per year for ST2PT_R WHRS 
1 For the other WHRS arrangements the shapes of the probability distributions for unreliability and unavailability costs

2 look similar.

3 It is interesting to compare the WHRS variants with and without redundant pumps. In Figure 18, the added cost

4 distributions due to unavailability and repair costs are displayed for ST2PT and ST2PT_R.

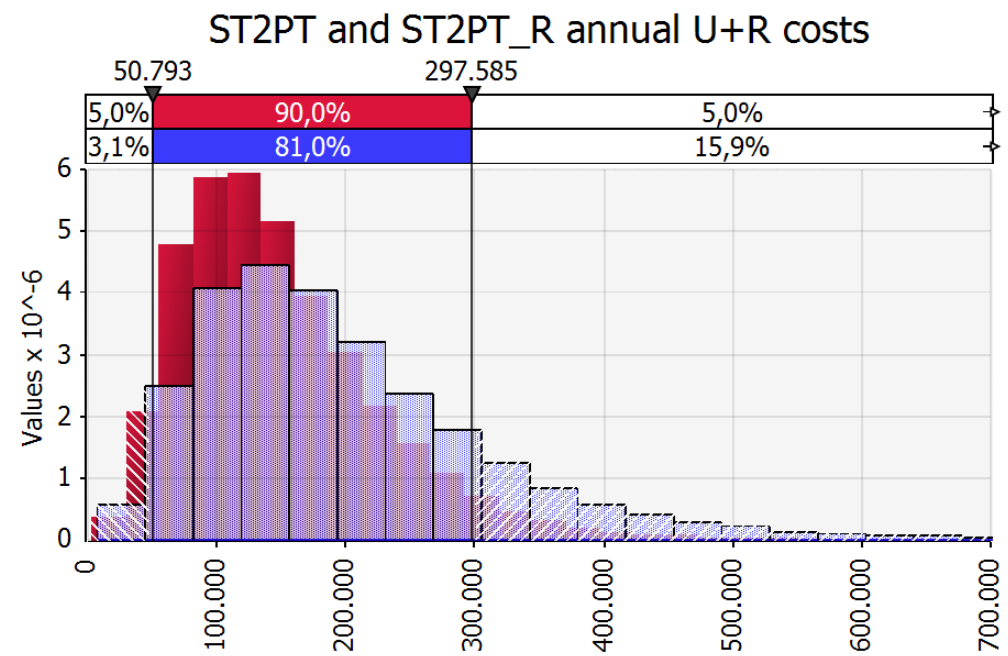

Figure 18: Probability distribution of repair and unavailability costs in USD per year for ST2PT (shaded blue) and ST2PT_R (red) WHRS

6 It can be noticed that the annual cost distribution for the ST2PT without redundant pumps, displayed in shaded blue, is

7 slightly more extended to the right compared to the ST2PT_R distribution in red. In terms of the mean value, this is a

8 difference in the annual unavailability and repair $(U+R)$ costs of 48,326 USD. This is nearly a factor of five of the

9 estimated additional costs for the two redundant pumps of $0.1 \%$ of the initial investment costs, indicating that this is

10 highly beneficial in our example. One of the reasons for the redundant pumps being so convincing here, are the

11 comparable large failure probabilities for the failure modes degraded and critical of around 1E-4 per hour, see Table 1.

12 The mean value for annual difference in U+R costs between ST1 and ST1_R is 20,659 USD, which is also several times

13 larger than the assumed costs for the redundant pump.

14 To put the costs shown in Figure 18 in a reasonable relation, Figure 19 displays the summed cost distributions due to

15 unavailability and repair as the share of the expected annual savings of the ST2PT_R WHRS. The mean value is given

16 with $7.2 \%$. 


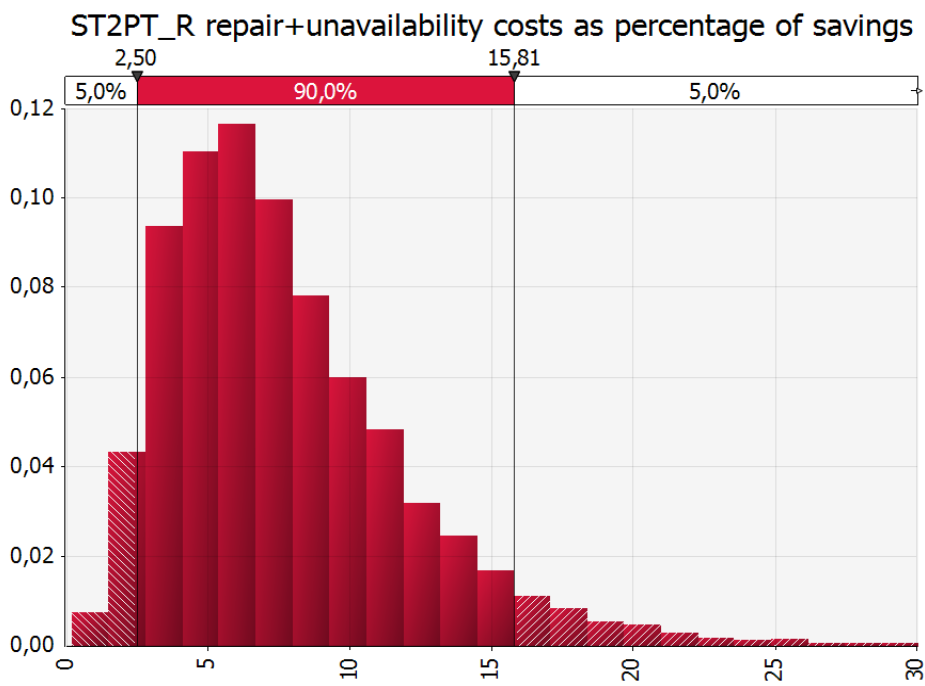

Figure 19: Probability distribution of unavailability and repair costs w.r.t. savings in \% for ST2PT_R

2 Table 13 contains the results for all five WHRS arrangements in terms of savings, costs due to unavailability and repair 3 and payback period. From Table 13 it can be obtained that the estimated unavailability and repair costs are around 8 to

$4 \quad 11 \%$ of the annual savings. Only for the PT WHRS this value is significantly lower, i.e. at $4 \%$, which is due to the

5 relatively low complexity and thus larger reliability of the PT. The largest relative costs are to be expected with the

6 single pressure steam turbine, which is due to the high complexity and no redundancy, e.g. when comparing it to ST2PT.

7 Here, especially the Om-ST1 output deviation with relatively high repair costs plays the most important role. In general,

8 it can be stated that the initial payback period calculation stated in row 3 , has to be adapted to also consider the non-

9 negligible effect of unavailability and repair costs. The updated payback period is given in the last row, revealing an

10 increase up to $13 \%$ for the ST1. For the WHRS variants with redundant pumps the updated payback period is shorter

11 compared to the scenario without redundant pumps, despite the slightly higher initial cost. The effect is a reduction

12 around 2 to 2.5 months of the payback period.

13 Table 13: Cost analysis mean value results

\begin{tabular}{lcccrc}
\hline & PT & \multicolumn{1}{c}{ ST1_R } & \multicolumn{1}{c}{ ST1 } & \multicolumn{1}{c}{ ST2PT_R } & \multicolumn{1}{c}{ ST2PT } \\
\hline Savings [million USD/year] & 0.72 & 0.83 & 0.83 & 1.96 & 1.96 \\
\hline Payback period [years] & 4.17 & 7.25 & 7.24 & 5.10 & 5.10 \\
\hline $\begin{array}{l}\text { Unavailability \& repair costs } \\
\text { [million USD/year] }\end{array}$ & 0.03 & 0.07 & 0.09 & 0.15 & 0.20 \\
\hline $\begin{array}{l}\text { Unavailability \& repair costs } \\
\text { w.r.t. savings [\%] }\end{array}$ & 4.16 & 8.96 & 11.46 & 7.65 & 10.24 \\
\hline $\begin{array}{l}\text { Payback period incl. U+R costs } \\
\text { [years] }\end{array}$ & 4.35 & 7.96 & 8.18 & 5.52 & 5.68 \\
\hline
\end{tabular}

14 


\section{Conclusions}

A method for combined thermodynamic and dependability analysis of different waste heat recovery system arrangements has been presented. The combined analysis is further used for useful prediction of the operational cost and savings, as well as costs of downtime and repair within an economic assessment for decision support on the most suited WHRS architecture.

Thermodynamic analysis is directly related to energy efficiency, whereas the dependability analysis reveals critical components and calculates the overall availability of the system. A special focus was set on investigating the use of redundant components. The benefits of redundant pumps as well as a comparison of different waste heat recovery variants have been performed within an economic analysis based on Monte Carlo simulations. A typical seagoing vessel with corresponding operational profile has been investigated in some detail, showing significant saving potentials:

11 firstly, by the use of a suitably dimensioned WHRS and secondly, by using redundant parts at critical points within the

12 WHRS. The analysis confirms that while WHRS requires large initial investment, the payback time is short, in the order 13 of a few years.

14 The methodology we have presented is rather generic in nature, at least in most of its components. In the future, we 15 intend to use this technique to examine other parts of new ship energy systems, for example battery and hybrid systems.

\section{REFERENCES}

Adamkiewicz, A., Wietrzyk, B., 2012, Marine Turbine Applications in Waste Heat Recovery Systems, Journal of Polish CIMAC, Faculty of Ocean Engineering \& Ship Technology, Gdansk University of Technology.

Aizpurua, J.I., Muxika, E., 2013. Model-Based Design of Dependable Systems : Limitations and Evolution of Analysis and Verification Approaches. Int. J. Adv. Secur. 6, 12-31.

Al-Hobo, A. H., Salamah, M. S., 2013 Design Of Dual Pressure Heat Recovery Steam Generator For Combined Power Plants, Iraq, Mosul University, Mechanical Engineering Department, technical report.

Arnold, A., Point, G., Griffault, A., Rauzy, A., 2000. The AltaRica formalism for describing concurrent systems. Fundam. Informaticae 40, 109-124.

Batteux, M., Prosvirnova, T., Rauzy, A., Kloul, L., 2013. The AltaRica 3.0 project for model-based safety assessment, in: 11th IEEE International Conference on Industrial Informatics (INDIN). IEEE, pp. 741-746.

Benvenuto, G., Campora, U., Trucco, A., 2014. Comparison of ship plant layouts for power and propulsion systems with energy recovery. J. Mar. Eng. Technol. 13, 3-15.

Benvenuto, G., Trucco, A., Campora, U., 2014a. Optimization of waste heat recovery from the exhaust gas of marine diesel engines. Proc. Inst. Mech. Eng. Part M J. Eng. Marit. Environ. 230, 83-94.

Bialystocki, N., Konovessis, D., 2016. On the estimation of ship's fuel consumption and speed curve: A statistical approach. J. Ocean Eng. Sci. 1, 157-166. doi:10.1016/j.joes.2016.02.001 Transf. - Spec. Sect. Adv. Autom. Verif. Crit. Syst. 9, 5-24. 
Bunkerworld, S\&P Global Platts, [WWW Document]. URL http://www.bunkerworld.com/prices/ (accessed 26.9.17)

Chaibakhsh, A., Ghaffari, A., 2008, Steam turbine model, Simulation Modelling Practice and Theory, Vol. 16, 11451162. doi:10.1016/j.simpat.2008.05.017

Collins, E., Dvorack, M., Mahn, J., Mundt, M., Quintana, M., 2009. Reliability and availability analysis of a fielded photovoltaic system, in: 34th IEEE Photovoltaic Specialists Conference (PVSC). pp. 2316--2321.

Dimopoulos, G.G., Georgopoulou, C.A., Stefanatos, I.C., Zymaris, A.S., Kakalis, N.M.P., 2014. A general-purpose process modelling framework for marine energy systems. Energy Convers. Manag. 86, 325-339. doi:10.1016/j.enconman.2014.04.046

Energetics, Incorporated, 2004, Technology Roadmap Energy Loss Reduction and Recovery in Industrial EnergySystems, U.S. Department of Energy, Office of Energy Efficiency and Renewable Energy.

Esary, J.D., Proschan, F., 1963. Coherent Structures of Non-Identical Components. Technometrics 5, 191-209.

ESI ITI GmbH, 2017. SimulationX [WWW Document]. URL http://www.simulationx.com/ (accessed 1.1.17).

Feiler, P., Rugina, A., 2007. Dependability Modeling with the Architecture Analysis \& Design Language (AADL), Tech. Rep. Software Engineering Institute, Carnegie Mellon University.

Fenelon, P., McDermid, J.A., 1993. An Integrated Toolset For Software Safety Analysis. J. Syst. Softw. 21, 279-290.

Freund, M., Magdanz, A., Jungnickel, T., 2014. Advanced ship energy calculation. Sh. Offshore 4, 22-26.

Ginnetti, A., Lampe, J., Magdanz, A., 2015. Energy Simulation for Waste Heat Recovery Systems, in: International Conference on Computer Applications in Shipbuilding. pp. 245-253.

Goldstick, R.K., Thumann, A., 1985, Principles of waste heat recovery, Association of Energy Engineers, Atlanta, OSTI Id. 6233670.

Guarin, L., Konovessis, D., Vassalos, D., 2009. Safety level of damaged RoPax ships: Risk modelling and costeffectiveness analysis. Ocean Eng. 36, 941-951. doi:10.1016/j.oceaneng.2009.06.005

Haghifam, M. R., Manbachi, M., 2011. Reliability and availability modelling of combined heat and power (CHP) systems. Int. J. Electr. Power Energy Syst. 33, 385-393. doi:10.1016/J.IJEPES.2010.08.035

Joshi, A., Heimdahl, M.P.E., Miller, S.P., Whalen, M.W., 2006. Model-based Safety Analysis. NASA Technical Report, NASA/CR-2006-213953. NASA Langley Research Center, Hampton, VA, USA.

Junior, C., Jaensch, D., Dingel, O., 2016, Energy and Thermal Management, Air Conditioning, Waste Heat Recovery, 1st ETA Conference, December 1-2, 2016, Berlin, Germany, Springer.

Kabir, S., 2017. An overview of Fault Tree Analysis and its application in model-based dependability analysis. Expert Syst. Appl. 77, 114-135. doi:10.1016/j.eswa.2017.01.058

Kabir, S., Papadopoulos, Y., Walker, M., Parker, D., Aizpurua, J.I., Lampe, J., Rüde, E., 2017. A model-based extension to HiP-HOPS for dynamic fault propagation studies, in: 5th International Symposium on Model-Based Safety and Assessment. pp. 163-178.

Koeppel, G., Andersson, G., 2009. Reliability modeling of multi-carrier energy systems. Energy 34, 235-244. doi:10.1016/J.ENERGY.2008.04.012

Lampe, J., Freund, M., 2013. Energy savings in the cooling water circuit of a container vessel. Sh. Offshore 1, 16-19.

Loer, K., Harrison, M.D., 2006. An integrated framework for the analysis of dependable interactive systems (IFADIS): Its tool support and evaluation. Autom. Softw. Eng. 13, 469-496. doi:10.1007/s10515-006-7999-y

Magott, J., Skrobanek, P., 2012. Timing analysis of safety properties using fault trees with time dependencies and timed state-charts. Reliab. Eng. Syst. Saf. 97, 14-26. doi:10.1016/j.ress.2011.09.004

41 MAN Diesel \& Turbo, 2011. TCS-PTG Savings with extra power. Report $n^{\circ}$ D2366350EN-N1, Germany.

MAN Diesel \& Turbo, 2012. Waste heat recovery system (WHRS) for reduction of fuel consumption, emissions and EEDI. Report $n^{\circ}$ 5510-0136-01, Denmark. 
Nagarajan, T Vijiyasamundiswary, S Kumar, P.S., 2013. Reliability and cost analysis of hybrid renewable energy systems, in: International Conference on Computation of Power, Energy, Information and Communication (ICCPEIC). pp. 84-88.

Olszewski, M. Hilenbrand, S.J. Reed, S.A., 1976, Waste heat vs conventional systems for greenhouse environmental control: An economic assessment.

OREDA, 2009. Offshore Reliability Data, 5th Edition. SINTEF Industrial Management.

Palisade Corporation, 2015. @RISK, Risk Analysis and Simulation Add-In for Microsoft ${ }^{\circledR}$ Excel, User’s Guide, Version 7.

Papadopoulos, Y., Mcdermid, J., Sasse, R., Heiner, G., 2001. Analysis and synthesis of the behaviour of complex programmable electronic systems in conditions of failure. J. Reliab. Eng. Syst. Saf. 71, 229-247.

Papadopoulos, Y., Walker, M., Parker, D., Sharvia, S., Bottaci, L., Kabir, S., Azevedo, L., Sorokos, I., 2016. A synthesis of logic and bio-inspired techniques in the design of dependable systems. Annu. Rev. Control 41, 170-182. doi:10.1016/j.arcontrol.2016.04.008

Papadopoulos, Y., Walker, M., Parker, D., Rüde, E., Hamann, R., Uhlig, A., Grätz, U., Lien, R., 2011. Engineering failure analysis and design optimisation with HiP-HOPS. Eng. Fail. Anal. 18, 590-608. doi:10.1016/j.engfailanal.2010.09.025

Reay, D.A., Heat Recovery Systems, E \& F.N.Span, London, 1979.

18 Rolls-Royce, 2010. Hybrid shaft generator propulsion system upgrade. HSG 0810, Norway.

Rüde, E., Walker, M., Papadopoulos, Y., Securius, P., D, P., 2012. Experience from Application of Semi-Automatic Fault Tree Synthesis to Reliability and Availability Analysis of Ship Systems, in: ISOPE Conference.

21 Thumann, A., 1983, Waste Heat Recovery Book, Spon Press, ISBN-13: 978-0915586646.

Tian, Z., Seifi, A.A., 2014. Reliability Analysis of Hybrid Energy System. Int. J. Reliab. Qual. Saf. Eng. 21, 1-9. doi:10.1142/S0218539314500119

Troy, A., 2014. Requirements Modeling and Fault Tree Analysis for Modelica, in: 17th ITI Symposium.

Trucco, A., 2012. Energetic optimization and pollutant emissions reduction of marine diesel engines. M.Sc. thesis (in Italian), DITEN - University of Genoa.

Tsatsaronis, G., 1993. Thermoeconomic analysis and optimization of energy systems. Prog. Energy Combust. Sci. 19, 227-257. doi:10.1016/0360-1285(93)90016-8

29 Vesely, W.E., Stamatelatos, M., Dugan, J., Fragola, J., Minarick, J., Railsback, J., 2002. Fault tree handbook with

Wang, J. J., Fu, C., Yang, K., Zhang, X. T., Shi, G. Zhai, J., 2013. Reliability and availability analysis of redundant aerospace applications. NASA Office of Safety and Mission Assurance, Washington DC.

33 Wärtsilä, 2007. Waste heat recovery (WHR): fuel saving with less emissions. Tech. Report.

Zhao, X., Liu, F., Fu, B., Fang, N., 2017. Reliability analysis of hybrid multi-carrier energy systems based on entropybased Markov model. Proc. Inst. Mech. Eng. Part O J. Risk Reliab. 230, 561-569. doi:10.1177/1748006X16663056 2013, Shanghai, International Council On Combustion Engines, paper no. 279. 